\title{
PRESUPUESTO DE CARBONO Y AUTORIZACIÓN DE PROYECTOS DE PRODUCCIÓN DE COMBUSTIBLES FÓSILES: EL CASO "GLOUCESTER RESOURCES LTD. V. MINISTER FOR PLANNING”
}

CARBON BUDGET AND FOSSIL FUEL PRODUCTION PLANNING: THE 'GLOUCESTER RESOURCES LTD. V. MINISTER FOR PLANNING' CASE

\author{
GASTÓN MEDICI-COLOMBO \\ Investigador predoctoral \\ CEDAT - Universitat Rovira i Virgili ${ }^{1}$ \\ gastonmedici@gmail.com
}

Fecha de recepción: 1 de abril de 2020 / Fecha de aceptación: 18 de mayo de 2020

RESUMEN: En Gloucester Resources Ltd. v. Minister for Planning (Australia, 2019) un tribunal ambiental respaldó la decisión administrativa de denegar el consentimiento a la apertura de una mina de carbón. Luego de un detenido análisis de sus impactos previstos, el juez concluyó que el proyecto había sido concebido no solo en el 'lugar equivocado' sino también en el 'momento equivocado' debido a su contribución al cambio climático. El caso objeto de estudio destaca por dos razones. En primer lugar, el tribunal utilizó, de manera inédita, el enfoque del presupuesto de carbono para evaluar la viabilidad climática del proyecto. En segundo lugar, la decisión afectó inmediatamente el panorama de planeamiento local, al ser utilizada por la autoridad administrativa para condicionar o denegar autorización a nuevos proyectos, lo que desató la reacción de ciertos sectores, principalmente del gobierno regional. Este trabajo analiza la resolución judicial y sus repercusiones a los fines de comenzar una

\footnotetext{
${ }^{1}$ Este trabajo ha recibido financiamiento del Programa de Investigación e Innovación Horizonte 2020 de la Unión Europea bajo el convenio de subvención Marie Sklodowska-Curie No. 713679 y de la Universitat Rovira i Virgili (URV); PROYECTO DE I+D: "La constitución climática global: gobernanza y Derecho en un contexto complejo" DER2016-80011-P. Cofinanciado por MINECO/FEDER, UE. El autor quiere agradecer a la Dra. Susana Borràs Pentinat, la Dra. Lucía Casado Casado, el Dr. Endrius Cocciolo y el Dr. Jordi Jaria i Manzano por sus estimulantes observaciones y recomendaciones a versiones preliminares del texto. Asimismo, a quienes, de forma anónima, revisaron este trabajo aportando valiosos comentarios.
} 
discusión sobre su relevancia para la futura toma de decisiones administrativas y judiciales, tanto en el escenario jurídico en el que el caso se desarrolló, como fuera de este ámbito.

RESUM: En el cas Gloucester Resources Ltd. v. Minister for Planning (Austràlia, 2019) un tribunal ambiental va recolzar la decisió administrativa de denegar el consentiment a l'obertura d'una mina de carbó. Un cop va analitzar en detall els seus impactes, el jutge va concloure que el projecte havia estat concebut en el lloc equivocat i en el moment equivocat, a causa de la seva contribució al canvi climàtic. El cas objecte d'estudi destaca per dues raons. En primer lloc, el tribunal va utilitzar, de manera inèdita, l'enfocament del pressupost de carboni per tal d'avaluar la viabilitat climàtica del projecte. A segon lloc, la decisió va afectar immediatament el planejament local, sent utilitzada per l'autoritat administrativa per tal de condicionar o denegar nous projectes. Això va comportar la reacció de certs sectors, principalment del govern regional. Aquest treball analitza la resolució judicial i les seves repercussions per tal d'iniciar una discussió sobre la seva rellevància en la futura presa de decisions administratives i judicials, tant en l'escenari jurídic en el qual el cas es va desenvolupar, com fora d'aquest àmbit.

ABSTRACT: In 'Gloucester Resources Ltd. v Minister for Planning’ (Australia, 2019) an environmental court upheld an administrative decision refusing approval for the opening of a coal mine. After carrying out a thorough analysis of the project's foreseeable impacts, the Judge concluded that the coal mine's proposed opening was not only in the wrong place but also at the wrong time, due to its contribution to climate change. The case stands out for two reasons. Firstly, the Court applied, for the first time, a carbon budget approach to examine the climate viability of the project. Secondly, the ruling had direct impact on the local planning scenario, in that the administrative authority started relying on the Judge's ruling in their process for approval or denial of new coal mine projects. This in turn triggered a reaction from a variety of sectors, including the regional government. The paper analyses the Court's ruling and its repercussions, and engages in a 
discussion on the case's relevance for future administrative and judicial decisionmaking, both within its legal context and beyond it.

PALABRAS CLAVE: Cambio climático - Litigio climático - Presupuesto de carbono - Acuerdo de París- Autorización administrativa.

PARAULES CLAU: Canvi climàtic - Litigi climàtic - Pressupost de carboni — Acord de París - Autorització administrativa.

KEYWORDS: Climate change - Climate litigation - Carbon budget - Paris Agreement - Planning.

SUMARIO: I. Introducción. II. Contexto: brecha de producción y presupuesto de carbono. 1. La brecha de producción de los combustibles fósiles. 2. El concepto del presupuesto de carbono global. III. El caso: "Gloucester Resources Ltd. v. Minister for Planning". 1. Antecedentes y presentación del caso. 2. Los impactos en el sistema climático como parámetro de viabilidad del proyecto. a) El argumento de la asociación civil. b) Los contraargumentos del promotor. c) Los considerandos del tribunal. 3. Resolución. IV. Discusión: la relevancia del caso. 1. Integración de los límites planetarios en la toma de decisiones. 2. Relevancia del caso como precedente para la toma de decisiones de planeamiento. 3. Relevancia del caso como precedente judicial. 4. Aplicación del enfoque del presupuesto de carbono. V. Conclusiones. VI. Bibliografía. VII. Normativa. VIII. Jurisprudencia.

\section{INTRODUCCIÓN}

El 23 de abril de 2019 Greta Thunberg se presentó ante el Parlamento británico, como ya lo había hecho previamente en la COP $24^{2}$ en Katowice y en el Foro Económico Mundial en Davos, y planteó ante los parlamentarios que:

Every time we make a decision... [w]e should no longer only ask: 'Have we got enough money to go through with this?' but also: 'Have we got enough of the carbon budget to spare to go through with this?' That should and must become the centre of our new currency ${ }^{3}$. (El resaltado no está en el original)

La activista hizo referencia aquí al presupuesto de carbono, es decir a la cantidad total de emisiones de gases de efecto invernadero (GEI) que puede ser emitida

\footnotetext{
2 Conferencia de las Partes en la Convención Marco de Naciones Unidas sobre el Cambio Climático (CMNUCC) en su vigésimo cuarta edición.

${ }^{3}$ Greta Thunberg, No One Is Too Small to Make a Difference, Penguin Books, Reino Unido, 2019, p. 64,65 .
} 
sin sobrepasar un aumento de temperatura determinado. El cálculo del presupuesto de carbono es una técnica científicamente consolidada, recogida tanto por el Grupo Intergubernamental de Expertos sobre el Cambio Climático (IPCC) en sus informes ${ }^{4}$ como por el Programa de las Naciones Unidas para el Medio Ambiente (PNUMA) a la hora de evaluar la brecha de emisiones existente entre los objetivos del Acuerdo de París —un aumento muy por debajo de $2^{\circ} \mathrm{C}$ y, en lo posible, de $1,5^{\circ} \mathrm{C}$ con respecto a los niveles preindustriales ${ }^{5}$ - y las contribuciones determinadas a nivel nacional (NDC) ${ }^{6}$. De acuerdo con Thunberg, la magnitud del presupuesto de carbono restante debería condicionar fuertemente la toma de decisiones en diversos niveles.

Este trabajo analiza la primera decisión judicial que utiliza el enfoque del presupuesto de carbono para evaluar la viabilidad de un proyecto de producción de combustibles fósiles, en este caso una mina de carbón en New South Wales (NSW), Australia. En Gloucester Resources Ltd. v. Minister for Planning ${ }^{7}$, una corte ambiental —Land and Environmental Court (NSWLEC) - respaldó la decisión del órgano administrativo de denegar autorización al proyecto minero, luego de evaluar sus impactos ambientales y sociales de carácter intra e intergeneracional, incluidos aquellos sobre el sistema climático, lo que determinó el abandono del proyecto. Interesa aquí comenzar una discusión sobre la relevancia de este caso, que engrosa cuantitativa, pero sobre todo

\footnotetext{
4 Joeri Rogelj et al., "2018: Mitigation Pathway Compatible with $1.5^{\circ} \mathrm{C}$ in the Context of Sustainable Development" en Valerie Masson-Delmonte et al., (eds.), Global Warming of $1,5^{\circ} \mathrm{C}$. An IPCC Special Report on the impacts of global warming of $1.5^{\circ} \mathrm{C}$ above pre-industrial levels and related global greenhouse gas emission pathways, in the context of strengthening the global response to the threat of climate change, sustainable development, and efforts to eradicate poverty, 2018, p. 108, <https://www.ipcc.ch/site/assets/uploads/sites/2/2019/05/SR15_Chapter2_Low_Res.pdf> [última consulta, 11 de febrero de 2020]

${ }^{5}$ Acuerdo de París, París, 12 de diciembre de 2015, United Nations Treaty Collection, artículo 2, <https://treaties.un.org/doc/Treaties/2016/02/20160215\%2006-03\%20PM/Ch_XXVII-7-d.pdf> [última consulta, 13 de febrero de 2020]

6 United Nations Environment Programme, "Emissions Gap Report 2019", p. 25, $<$ https://wedocs.unep.org/bitstream/handle/20.500.11822/30797/EGR2019.pdf?sequence=1\&is Allowed $=y>$ [última consulta, 11 de febrero de 2020]

7 New South Wales Land and Environmental Court, Gloucester Resources Limited v Minister for Planning [2019] NSWLEC 7, sentencia del 8 de febrero de 2019, <https://www.caselaw.nsw.gov.au/decision/5c59012ce4b02a5a800be47f> [última consulta, 13 de febrero de 2020]
} 
cualitativamente, el universo de la llamada litigación climática ${ }^{8}$, a los fines de comprender más detalladamente sus posibles repercusiones para la toma de decisiones administrativas y judiciales, tanto en el escenario jurídico en el que se desarrolló como fuera de este ámbito.

La primera sección presenta dos conceptos que sirven a la contextualización del caso: la 'brecha de producción' y el 'presupuesto de carbono'. La segunda sección expone la decisión judicial, resumiendo las argumentaciones desplegadas por los litigantes y los considerandos del juez. Finalmente, la tercera sección aborda la discusión sobre la relevancia del caso a partir de cuatro aristas: la integración de los límites planetarios en la toma de decisiones, la relevancia del caso para la práctica administrativa de planeamiento, su transcendencia como precedente judicial y, finalmente, la aplicación del enfoque adoptado por el juez.

\section{CONTEXTO: BRECHA DE PRODUCCIÓN Y PRESUPUESTO DE CARBONO}

\section{La brecha de producción de los combustibles fósiles}

La quema de combustibles fósiles es, largamente, la mayor fuente de contribución al cambio climático, representando el $75 \%$ de las emisiones de GEI y el $90 \%$ de las emisiones de $\mathrm{CO}_{2}{ }^{9}$. Para mantener una trayectoria compatible con las metas acordadas en el Acuerdo de París, las emisiones de esta fuente deben declinar rápida y significativamente, lo que implica que la mayoría de las

\footnotetext{
${ }^{8}$ Se han reportado más de 1400 casos en, al menos, 32 jurisdicciones. Joana Setzer y Rebecca Byrnes, "Global trends in climate change litigation: 2019 snapshot", Grantham Research Institute on Climate Change and the Environment, Centre for Climate Change Economics and Policy, London School of Economics and Political Science, Policy Report, 2019, p. 3. Existe cierta dificultad en definir qué se entiende por 'litigación climática' desde que, como resalta Hilson: "virtually all litigation could be conceived of as [climate change litigation]: after all, even the average contract dispute is like to have a carbon implication somewhere within it if ones looks hard enough". Chris Hilson, "Climate Change Litigation in the UK: An Explanatory Approach (or Bringing Grievance Back In)", en Fabrizio Fracchia y Massimo Occhiena (eds.), Climate Change: La Risposta del Diritto, Editoriale Scientifica, Nápoles, 2010, p. 421.

9 Stockholm Environment Institute et al., "The Production Gap: The discrepancy between countries' planned fossil fuel production and global production levels consistent with limiting warming to $1.5^{\circ} \mathrm{C}$ or $2^{\circ} \mathrm{C}$, $2019, \quad$ p. 8 , <http://productiongap.org/wpcontent/uploads/2019/11/Production-Gap-Report-2019.pdf> [última consulta, 11 de febrero de 2020]
} 
reservas probadas de combustibles fósiles debe permanecer en el subsuelo, sin explotar ${ }^{10}$.

Sin embargo, esto no parece estar siendo seriamente considerado por los gobiernos. Bajo el auspicio del PNUMA, en 2019 se presentó el informe titulado Production Gap que abordó la discrepancia entre la producción de combustibles fósiles planificada por los estados y los niveles de producción global consistentes con las metas de aumento de temperatura, acordadas en París. Los números presentados por el informe son más que inquietantes. Los gobiernos están planificando producir alrededor de un 53\% más de combustibles fósiles para 2030 de lo que sería consistente con una trayectoria de aumento de $2^{\circ} \mathrm{C}$. Brecha que aumenta hasta un $120 \%$ si se considera la meta de $1,5^{\circ} \mathrm{C}$. Si el horizonte temporal es 2040, la discrepancia se acentúa aún más: $110 \%$ para $2^{\circ} \mathrm{C}$ y $210 \%$ para $1,5^{\circ} \mathrm{C}^{11}$. Específicamente para el carbón, la brecha es más amplia, pues para 2030 los planes de producción de este combustible superan en un 150\% la trayectoria de $2^{\circ} \mathrm{C}$ y en un $280 \%$ la de $1,5^{\circ} \mathrm{C}^{12}$.

La brecha de producción no existe solo con respecto a las metas de aumento de temperatura fijadas en el Acuerdo de París, sino también con relación a los propios compromisos de los estados en sus NDC, lo que implica que es superior incluso a la ya alarmante brecha de emisión ${ }^{13}$. Según el informe, esto puede atribuirse a la escasa atención política dirigida a limitar la oferta de combustibles fósiles ${ }^{14}$. Debe notarse que la propia metodología de los inventarios nacionales de emisiones, de base territorial, no ayuda a promover este enfoque ${ }^{15}$. Aquellas emisiones producto de la quema de combustibles exportados serán responsabilidad de otro estado, lo que permite que existan países que, mientras

\footnotetext{
10 Ídem; Rogelj et al., "2018: Mitigation Pathways...", cit., p. 119; Sivan Kartha, Michael Lazarus y Kevin Tempest, "Fossil Fuel Production in a $2^{\circ} \mathrm{C}$ World: The Equity Implications of a Diminishing Carbon Budget", en Stockholm Environment Institute: Discussion Brief, 2016, p. 2, $<$ https://mediamanager.sei.org/documents/Publications/Climate/SEI-DB-2016-Equity-fossil-fuelproduction-rents-LR.pdf> [última consulta, 11 de febrero de 2020]

11 Stockholm Environment Institute et al., "The Production Gap...", cit, p. 14.

12 Ídem, p. 15.

13 Ídem, p. 17.

14 Ídem; véase Michael Lazarus y Harro van Asselt, "Fossil Fuel Supply and Climate Policy: Exploring the Road Less Taken", en Climatic Change, Vol. 150, 2018.

15 Stockholm Environment Institute et al., "The Production Gap...", cit., p. 17 y 23.
} 
ostentan una reducción de emisiones en sus NDC, pretenden expandir su producción fósil significativamente ${ }^{16}$.

Asimismo, el informe destaca que la expansión continua de la producción -y la consecuente ampliación de la brecha - es apuntalada por una combinación de medidas gubernamentales de apoyo al sector fósil. Los gobiernos no solo juegan un rol central en la autorización de la exploración y producción, sino que también impulsan la industria fósil mediante inversiones directas, financiación en investigación y desarrollo, gasto fiscal, exenciones impositivas y asunción de responsabilidad y riesgo, aún (y especialmente) cuando la demanda del producto no lo amerita ${ }^{17}$.

La situación particular de Australia es destacada por el informe que la describe como el líder mundial de exportación de carbón y el segundo mayor productor y exportador de gas natural licuado. Con el fuerte y múltiple apoyo del gobierno observa el informe - esta producción y exportación continuará en aumento, incluso pudiendo representar la mayor expansión de combustibles fósiles a nivel global. Según estas proyecciones, al mismo tiempo que su NDC promete una reducción de emisiones (territoriales) de entre el 26 y $28 \%$, las emisiones resultantes de su producción de fósiles prácticamente se duplicarán para 2030 en comparación a $2005^{18}$.

Se ha advertido, con preocupación, que esta apuesta sumerge a los estados en un carbon entanglement ${ }^{19}$ que obstaculiza las posibilidades de desarrollo de las

\footnotetext{
16 Ídem, p. 4.

17 Stockholm Environment Institute et al., "The Production Gap...", cit, p. 20 y ss. Véase como reciente ejemplo la creación de un barril 'criollo' para el sostenimiento de los precios para la explotación del yacimiento de Vaca Muerta en Argentina: Sebastián Penelli, "Regresa el barril "criollo" de petróleo a u\$s45 con fuerte respaldo de YPF, provincias y sindicatos", ámbito.com, 7 de mayo de 2020, <https://www.ambito.com/barril-criollo/regresa-el-petroleo-us45-fuerterespaldo-ypf-provincias-y-sindicatos-n5100804> [última consulta, 14 de mayo de 2020]

18 Ídem, p. 35.

19 Ángel Gurría, "The climate challenge: Achieving zero emissions", OECD, 9 de octubre de 2013 <http://www.oecd.org/about/secretary-general/the-climate-challenge-achieving-zeroemissions.htm> [última consulta, 20 de abril de 2020] El informe define este término como el proceso por el cual la dependencia de los gobiernos en la extracción de combustibles fósiles y sus retornos crea fuertes intereses en poner estos productos en el mercado, obstaculizando las posibilidades de progreso de la política climática, Stockholm Environment Institute et al., "The Production Gap...", cit, p. vi.
} 
políticas climáticas. De igual forma, que con ello se produce un carbon lock-in ${ }^{20}$ que asegura trayectorias de emisiones más altas, aún en contraposición a trayectorias menos carbono-intensivas que podrían proveer iguales o mejores beneficios económicos, ambientales y sociales ${ }^{21}$. De este modo, aumentan los riesgos, por un lado, de fracasar en el cumplimiento de las metas climáticas (con todo lo que ello conlleva) y, por otro, de que se produzcan grandes activos varados $^{22}$ con serias implicaciones para la economía del estado $y$, particularmente, para ciertas comunidades y trabajadores ${ }^{23}$.

\section{El concepto del presupuesto de carbono global}

Una manera simplificada de exponer la magnitud de la problemática de la producción continua ( $\mathrm{y}$ creciente) de combustibles fósiles para el cambio climático es a través del concepto del 'presupuesto de carbono'. Concepto que en los últimos años ha venido gozando de creciente centralidad en la ciencia y en la política climática ${ }^{24}$. Este describe la máxima cantidad de emisiones acumulativas de GEI que podrían ser 'permisibles', en consideración de las propiedades físicas del sistema climático, si se quiere permanecer por debajo de un límite de calentamiento políticamente acordado ${ }^{25}$. Así, representa una forma

20 Peter Erickson, et al., "Assessing carbon lock-in", Environmental Research Letters, Vol. 10, 2015. Según estos autores, se trata de la dinámica por la cual decisiones pasadas o presentes sobre las tecnologías de emisión de GEI, infraestructura, prácticas y sus redes de soporte restringen en el presente o en el futuro las posibilidades de recorrer caminos óptimos hacia objetivos de descarbonización.

21 Stockholm Environment Institute et al., "The Production Gap...", cit, p. 5, 21. Véase, por ejemplo, Ryan Rafaty, Sugandha Srivastav y Björn Hoops, "Revoking Coal Mining Permits: An Economic and Legal Analysis", Climate Policy, 2020. Afirmando que la (improbable) revocación de licencias de minería de carbón implicaría beneficios netos para gobiernos y comunidades.

${ }^{22} \mathrm{El}$ informe sobre la brecha de producción los define como activos que sufren, de manera inesperada o prematura, pérdidas sustanciales, valuaciones a la baja o se convierten en pasivos como resultado de la transición energética u otros riesgos ambientales. Stockholm Environment Institute et al., "The Production Gap...", cit, p. vi.

${ }^{23}$ Greg Muttit, "The Sky's Limit: Why the Paris Climate Goals Require a Managed Decline of Fossil Fuel Production", Oil Change International, 2016. Stockholm Environment Institute et al., "The Production Gap...", cit, p. 17.

${ }^{24}$ Bård Lahn, "A History of the Global Carbon Budget", en WIREs Climate Change, núm. e636, 2020, p.1.

${ }^{25}$ Ídem, p. 2, 3; Joeri Rogelj, et al., "“Estimating and tracking the remaining carbon budget for stringent climate targets", en Nature, Vol. 571, núm. 7765, 2019, p. 335. 
simple y transparente de conectar los límites físicos del Sistema Tierra con las implicaciones de la política climática ${ }^{26}$.

Si bien su gestación data de 1989, en aquel entonces —recuerda Lhan- era visto como científicamente deficiente desde que se observaban, en los modelos climáticos para un mismo aumento de temperatura, diferencias no triviales en la cantidad acumulativa de emisiones dependiendo de cómo estas se distribuyeran en el tiempo. Esto significaba que la cantidad de emisiones 'permisibles' debía ser calculada en base a trayectorias de emisiones y no en base a emisiones acumulativas. Por esta razón, el peso del concepto fue mínimo en las décadas de los 90' y del 00'27.

Sin embargo, de acuerdo con Lahn, esto cambió a partir de dos causas. Por un lado, sobre finales de la primer década del nuevo milenio se consolidó un consenso político en establecer una meta consistente en un aumento de temperatura determinado. Por otro, un entendimiento científico más profundo de las interacciones entre el sistema climático y el ciclo de carbono llevó a la certeza de que las emisiones acumulativas y el aumento de temperatura estaban casi linealmente correlacionados. En este entender, cada tonelada de $\mathrm{CO}_{2}$ añade la misma cantidad de calentamiento, sin importar dónde ni cuándo se emita y, por lo tanto, cualquier meta de temperatura está necesariamente asociada con una cantidad fija de emisiones 'permisibles'28. Esto condujo al convencimiento de que el concepto del presupuesto de carbono global provee la forma más científicamente robusta de establecer metas en la política climática, incluso por sobre las tasas de emisión y las concentraciones de $\mathrm{CO}_{2}$ en la atmósfera ${ }^{29}$.

En consideración de ello, el IPCC empleó el concepto en sus informes de 2014 y 2018. En su informe síntesis de 2014, el organismo presentó la cuantificación de un escaso presupuesto de carbono global que contrastó con las cuantiosas reservas de carbón, petróleo y gas existentes a nivel global ${ }^{30}$. Por su parte, en

\footnotetext{
26 Ídem, p. 338.

27 Lhan, "A History...., cit, p. 3.

${ }^{28}$ Rogelj, et al., "“Estimating and tracking the remaining carbon budget...", cit., p. 335.

${ }^{29}$ Lhan, "A History...", cit, p. 3, 4. Malte Meinshausen et al., "Greenhouse-gas emission targets for limiting global warming to $2^{\circ} \mathrm{C}$ ", en Nature, Vol. 458, núm. 7242, 2009.

30 Rajendra Kumar Pachauri et al., 2014: Cambio climático 2014: Informe de síntesis. Contribución de los Grupos de trabajo I, II y III al Quinto Informe de Evaluación del Grupo
} 
su informe de 2018, volvió a difundir una cuantificación, pero esta vez lo hizo mediante un abanico de posibles presupuestos, exponiendo la complejidad de alcanzar una cifra única y certera debido a las incertidumbres respecto del comportamiento del sistema climático ${ }^{31}$. Esto no le impidió, sin embargo, resaltar que las emisiones ya comprometidas en la infraestructura de producción existente excederían en más de dos tercios el presupuesto de carbono restante ${ }^{32}$, dejando de lado las resultantes del agotamiento de las reservas ${ }^{33}$.

Es notable, sin embargo, la ausencia del concepto en el régimen jurídico internacional del cambio climático. Esto se ha relacionado con cierto escepticismo entre quienes consideran que su simplicidad, lejos de facilitar la toma de decisiones políticas, podría endurecer conflictos distribucionales entre estados $^{34} \mathrm{e}$ incrementar la resistencia por parte de ciertos actores influyentes del sector energético ${ }^{35}$. En este sentido, el concepto se convertiría en una especie de verdad incómoda para los estados y otros actores relevantes, a la vez que en una idea especialmente atrayente para la sociedad civil organizada a la hora de enfatizar las brechas de la política climática y la necesidad de dejar sin explotar grandes reservas de combustibles fósiles ${ }^{36}$ y de desinvertir en los carbon majors $^{37}$.

En el caso aquí analizado, como se verá a continuación, se inserta este concepto en el entramado jurídico-político que hace a la toma de decisiones de planeamiento, otorgándole entidad suficiente para, al menos, limitar la viabilidad de nuevos proyectos de infraestructura fósil en sede administrativa.

\footnotetext{
Intergubernamental de Expertos sobre el Cambio Climático, 2014, p. 64, <https://www.ipcc.ch/site/assets/uploads/2018/02/SYR_AR5_FINAL_full_es.pdf> [última consulta, 11 de febrero de 2020]; Lhan, "A History...", cit., p. 4.

${ }^{31}$ Rogelj et al., "2018: Mitigation Pathways...", cit., p. 108.

32 Ídem, p. 113.

${ }^{33}$ Kartha, Lazarus y Tempest, "Fossil Fuel Production..." cit., p. 2.

${ }^{34} \mathrm{La}$ dificultad política de atribuir presupuestos de carbono nacionales resulta evidente. Sobre la distribución del presupuesto de carbono entre grupos de países, véase, por ejemplo, Juan Antonio Duro, José-Manuel Giménez-Gómez y Cori Vilella, "The Allocation of $\mathrm{CO}_{2}$ emissions as a claims problem", en Energy Economics, Vol. 86, 2020.

${ }^{35}$ Lhan, "A History...", cit., p. 4.

${ }^{36}$ Véase el movimiento denominado Keep It in the Ground, <http://keepitintheground.org/> [última consulta, 25 de mayo de 2020]

37 Ídem, p. 4, 5. Véase por ejemplo la plataforma 350.org, <350.org > [última consulta, 25 de mayo de 2020]
} 


\section{EL CASO: "GLOUCESTER RESOURCES LTD. V. MINISTER FOR PLANNING"}

\section{Antecedentes y presentación del caso}

En Gloucester Resources Ltd. v. Minister for Planning, una empresa Gloucester Resources Limited (GRL) - decidió recurrir la decisión del órgano de planeamiento local _Independent Planning Commission (IPC) ${ }^{38}$ - de denegar el consentimiento al desarrollo de un proyecto minero -Rocky Hill Coal Project ${ }^{39}$ - con la capacidad de producir 21 millones de toneladas de carbón para la manufactura de acero en un período de 16 años. Las razones ofrecidas por la autoridad fueron: (a) que la actividad propuesta en tal localización se encontraría en directa contravención con los objetivos de las zonas respectivas; (b) que su impacto visual residual sería significativo; y (c) que el proyecto no podría ser catalogado como de interés público ${ }^{40}$. Previo a esta decisión, la población local había presentado numerosas inquietudes sobre los previsibles impactos del proyecto, incluyendo aquellos relativos al cambio climático ${ }^{41}$, los que sin embargo no fueron alegados en la decisión administrativa denegatoria.

La apelación, de acuerdo con la NSW Environmental Planning and Assessment Act (EPA Act $)^{42}$, derivó en la intervención de la NSWLEC, tribunal judicial especializado en materia ambiental, que debía actuar en el caso asumiendo el rol que previamente había desempeñado la autoridad administrativa ${ }^{43}$. Es decir, debía realizar una revisión de mérito u oportunidad de la decisión administrativa

\footnotetext{
${ }^{38}$ La IPC, como su nombre lo indica, es una agencia independiente establecida por ley que, entre otras funciones, determina el consentimiento de proyectos de desarrollo significativos; Independent Planning Commission, "About us", <https://www.ipcn.nsw.gov.au/about-us> [última consulta, 7 de octubre de 2019]

39 Rocky Hill Coal Project, "Location", <https://www.rockyhillproject.com.au/projectoverview/location/> [última consulta, 7 de octubre de 2019]

${ }^{40}$ New South Wales Land and Environmental Court, Gloucester Resources..., cit., párr. 22.

41 Ídem, párr. 6 y 20.

42 Environmental Planning and Assessment Act 1979 No. 203, Division 8.3 Appealsdevelopments consents. <https://www.legislation.nsw.gov.au/\#/view/act/1979/203/part8/div8.3> [última consulta, 25 de mayo de 2020]

${ }_{43}$ New South Wales Land and Environmental Court, Gloucester Resources..., cit., párr. 7; Environmental Planning and Assessment Act 1979 No. 203, 8.14.
} 
y no un control de su legalidad ${ }^{44}$. La resolución del tribunal constituiría la decisión final sobre el proyecto, sin perjuicio de un posible recurso ante la NSW Court of Appeal, a los efectos de una revisión de legalidad ${ }^{45}$.

Abierto el proceso en sede judicial, las partes realizaron las alegaciones del caso y, en apoyo a la decisión administrativa, una asociación civil - Groundswell Gloucester - intervino planteando expresamente los impactos climáticos del proyecto. Con ello, en resumidas cuentas, las razones contra la actividad analizadas por el tribunal fueron: (a) la incompatibilidad del proyecto con los usos de suelo; (b) los impactos visuales; (c) los impactos sociales adversos, incluyendo aquellos generados por el ruido y el polvo; (d) la incertidumbre y posible sobreestimación de los beneficios económicos y públicos del proyecto en relación con sus costes; y (e) la falta de interés público en el desarrollo del proyecto debido a (i) las razones anteriores y (ii) su contradicción con los 'principios de desarrollo ecológicamente sostenible'46, en consideración de que sus emisiones directas e indirectas de GEI contribuirían al cambio climático ${ }^{47}$.

Mediante una extensa resolución, el tribunal —representado en el caso por el juez Brian Preston - realizó un detallado y por demás interesante análisis de cada una de las razones que dieron lugar a la no aprobación del proyecto, el que ameritaría un comentario más extenso. Aquí, sin embargo, interesa abordar exclusivamente la razón relativa a los posibles impactos en el sistema climático. La aceptación por parte del tribunal de esta razón, introducida vigorosamente

\footnotetext{
${ }^{44}$ New South Wales Land and Environmental Court, "Class 1: environmental planning and protection appeals" <http://www.lec.justice.nsw.gov.au/Pages/types_of_disputes/class_1/class_1.aspx> [última consulta, 8 de octubre de 2019] Este tribunal, establecido por ley en 1979, tiene una amplia jurisdicción que incluye revisión de mérito, revisión de legalidad, ejecución civil, enjuiciamiento penal, apelaciones penales y demandas civiles sobre diversas materias entre las que se cuentan planeamiento, ambiente, suelo y minería. New South Wales Land and Environmental Court, "About us" <http://www.lec.justice.nsw.gov.au/Pages/about/about.aspx> [última consulta, 1 de abril de 2020]

45 New South Wales Land and Environment Court Act 1979 No. 204, Section 57, <https://www.legislation.nsw.gov.au/\#/view/act/1979/204/part5/div2/sec57> [última consulta, 27 de mayo de 2020]

46 Principles of ecologically sustainable development, New South Wales Protection of the Environment Administration Act 1991 No. 60. Part 3.6(2), $<$ https://www.legislation.nsw.gov.au/ /pdf/view/act/1991/60/whole> [última consulta, 4 de junio de 2020]

${ }^{47}$ New South Wales Land and Environmental Court, Gloucester Resources..., cit., párr. 24.
} 
por la asociación civil, convierte al caso en un precedente innovador en un área en expansión como lo es la litigación climática.

\section{Los impactos en el sistema climático como parámetro de viabilidad del proyecto}

a) El argumento de la asociación civil

Como se mencionó, en su intervención en el proceso, Groundswell Gloucester planteó - a partir de los informes del IPCC y de la actuación como perito de parte del científico Will Steffen-que las emisiones directas e indirectas del proyecto -incluyendo las provenientes de la quema del carbón por terceras partes (Scope 3 emissions) ${ }^{48}$ - resultarían inconsistentes con el presupuesto de carbono disponible según las metas de aumento de temperatura fijadas en el Acuerdo de París ${ }^{49}$.

Específicamente, alegó (a) que cualquier análisis del presupuesto de carbono llevaría a la conclusión de que la quema de combustibles fósiles debe ser eliminada progresiva pero rápidamente; (b) que ello implica que la mayoría de las reservas de combustibles fósiles existentes en el mundo deben quedar sin explotar y, por lo tanto, (c) que no deberían permitirse nuevos desarrollos de producción ${ }^{50}$ —entre ellos el de Rocky Hill-, los cuales serían inconsistentes con el objetivo del Acuerdo de París ${ }^{51}$.

\section{b) Los contraargumentos del promotor}

\footnotetext{
48 Las que estarían dentro de las llamadas 'downstream Scope 3 emissions'. 'Scope 3' hace referencia a emisiones consecuencia de actividades de la empresa, pero que ocurren a partir de fuentes no poseídas o controladas por ella. World Resources Institute y World Business Council for Sustainable Development, "The Greenhouse Gas Protocol: A Corporate Accounting and Reporting Standard", 2004, p. 25, <https://ghgprotocol.org/sites/default/files/standards/ghgprotocol-revised.pdf> [última consulta, 11 de febrero 2020] Este tipo de emisiones representan, largamente, la mayor parte de las emisiones vinculadas al proyecto.

${ }^{49}$ New South Wales Land and Environmental Court, Gloucester Resources..., cit., párr. 422.

${ }^{50}$ Pues los que están actualmente en explotación son suficientes para sobrepasar por sí solos el presupuesto.

51 New South Wales Land and Environmental Court, Gloucester Resources..., cit., párr. 445-447.
} 
GRL rechazó esta argumentación. En primer lugar, sostuvo que no existe ley o instrumento internacional que haya estipulado una política de prohibición total de nuevas minas de carbón. Los estados, alegó GRL, tienen total discreción en determinar cómo alcanzarán las reducciones de emisiones ${ }^{52}$ por lo que el tribunal estaría violando su jurisdicción —excediendo su rol—si adoptase una política de prohibición general de proyectos de este tipo ${ }^{53}$. En segundo lugar, manifestó GRL, la decisión no puede contemplar los posibles impactos de las emisiones indirectas a producirse fuera de la jurisdicción australiana al quemarse el carbón exportado. Alegó al respecto que un Estado Parte del régimen internacional del cambio climático debe responder solamente por las emisiones generadas bajo su jurisdicción ${ }^{54}$. En tercer lugar, argumentó que, de no cubrirse la demanda de carbón por proyectos mineros en suelo australiano, esta sería cubierta por producción en otra parte del mundo (por ej. India o Indonesia) con peores resultados en lo climático, lo económico y social ${ }^{55}$. Por lo tanto, no habría un diferencial positivo, sino más bien negativo, entre los escenarios 'con proyecto' y 'sin proyecto'. Finalmente, en relación con el punto anterior, resaltó que, en todo caso, las emisiones estarían justificadas ya que el carbón a producir es un insumo difícilmente sustituible para la producción de acero, indispensable para la sociedad actual ${ }^{56}$.

\section{c) Los considerandos del tribunal}

El juez abordó, en primer lugar, las alegaciones de GRL para luego razonar sobre la argumentación planteada por la asociación civil. Así es que, primeramente y en contraposición a lo sostenido por el promotor, el magistrado determinó, interpretando la normativa nacional (EPA Act), que todas las emisiones, directas e indirectas -incluyendo aquellas de Scope 3-, eran relevantes y debían ser consideradas a la hora de tomar la decisión ${ }^{57}$. Según el juez, referencias

\footnotetext{
52 Ídem, párr. 452. Al respecto, GRL planteó la necesidad de considerar el principio de eficiencia en la mitigación a los fines de no desestabilizar la economía, ídem, párr. 459.

53 Ídem.

54 Ídem, párr. 453.

55 Ídem, párr. 484.

56 Ídem, párr. 483.

57 Ídem, párr. 487.
} 
normativas a 'dowstream emissions', 'impactos acumulativos del cambio climático' e 'impactos probables del proyecto', a la vez que los principios de precaución y de equidad intergeneracional, justifican esta amplia consideración ${ }^{58}$, en consonancia con lo resuelto en diversos precedentes jurisprudenciales domésticos ${ }^{59}$ y de jurisdicción norteamericana ${ }^{60}$.

En segundo lugar, el juez observó que todas las emisiones de GEI contribuyen al cambio climático, sin importar si en perspectiva global representan solo una pequeña fracción ${ }^{61}$. Al respecto, recordó que cierta jurisprudencia -incluidos los leading cases 'Massachusetts v. EPA' y 'Urgenda Foundation v. The State of the Netherlands ${ }^{62}$ - ya había reconocido que el cambio climático es producto de emisiones acumuladas de innumerables fuentes individuales y que su solución depende de la reducción de esas innumerables fuentes individuales ${ }^{63}$. En este sentido, el magistrado consideró que existe un nexo causal entre las emisiones acumulativas del proyecto y el cambio climático y sus consecuencias ${ }^{64}$.

Así, la aprobación del proyecto contradiría las acciones requeridas para curvar las emisiones tan pronto como fuera posible a los fines de alcanzar la neutralidad carbónica en la segunda mitad del siglo, meta aceptada globalmente en el artículo 4.1 del Acuerdo de París y que el gobierno local ha respaldado65. Si bien —reconoce el magistrado- ni el Acuerdo de París, ni las NDC de Australia, ni la legislación local prescriben cómo deben cumplirse las metas de reducción de emisiones, ni prohíben la aprobación de nuevas fuentes, la explotación y la quema de nuevas reservas no puede ayudar a alcanzar la rápida y profunda

\footnotetext{
58 Ídem, párr. 491-498.

59 Ídem, párr. 499-503, El juez menciona: 'Australian Conservation Foundation v. Latrobe City Council'; 'Gray v. Minister for Planning'; 'Coast and Country Association Queensland Inc. v. Smith'; 'Wollar Property Progress Association Inc. v. Wilpinjong Coal Pty Ltd'.

60 Ídem, párr. 504-512, El magistrado menciona: 'Border Power Plant Working Group v Department of Energy'; 'Mid States Coalition for Progress v Surface Transportation Board'; 'Montana Environmental Information Centre v US Office of Mining'; 'Sierra Club v Federal Energy Regulatory Commission'; 'San Juan Citizens Alliance v United States Bureau of Land Management'.

61 Ídem, párr. 515.

62 'Australian Conservation Foundation v. Latrobe City Council'; 'Gray v. Minister for Planning'; 'Massachusetts v. EPA'; 'Urgenda Foundation v. The State of the Netherlands' $(2015,2018)$. 63 Ídem, párr. 516-524.

64 Ídem, párr. 525, "The Project's cumulative GHG emission will contribute to the global total of GHG concentrations in the atmosphere. The global total of GHG concentrations will affect the climate system and cause climate change impacts".

65 Ídem, párr. 526.
} 
mitigación necesaria para el cumplimiento de los objetivos climáticos de mediano o largo plazo asumidos ${ }^{66}$.

En tercer lugar, el magistrado descartó las alegaciones por las que GRL entendía que, a pesar de esta supuesta contraindicación, el proyecto debía ser igualmente aprobado. Primero, observó que no se había dispuesto ninguna medida de mitigación de emisiones ni se había probado que estas fueran a ser compensadas por reducciones más eficientes en otras fuentes. Por lo tanto, no sería racional aprobar el proyecto amparándose en la posibilidad teórica de mitigación por una acción inespecífica e incierta en el futuro o debido a que, especulativamente, sería posible reducir emisiones de manera más costeefectiva ${ }^{67}$.

Segundo, tampoco consideró probado el hecho de que la demanda de carbón vaya a ser cubierta por otras nuevas fuentes (argumentos conocidos como 'market substitution' y 'carbon leakage') ${ }^{68} \mathrm{y}$, por lo tanto, que no existan diferencias positivas en la situación climática entre el escenario 'con proyecto' y el escenario 'sin proyecto'. Sobre la hipótesis de que nuevos proyectos en estados en vías de desarrollo puedan cubrir la demanda no cubierta por este proyecto, el juez realizó dos interesantes observaciones. Por un lado, que los estados desarrollados tienen la responsabilidad de tomar el liderazgo en la lucha contra el cambio climático, según lo establecido en los distintos instrumentos internacionales sobre la materia ${ }^{69}$. Por otro lado, que existe un error lógico en considerar que impactos ambientales inaceptables de un proyecto puedan volverse aceptables debido a que un proyecto alternativo, hipotético e incierto pueda causar el mismo impacto inaceptable ${ }^{70}$.

Tercero, el magistrado descartó que las nuevas emisiones del proyecto puedan estar justificadas por el mero hecho de que el carbón a producir vaya a ser utilizado para la manufactura de acero, fundamental para la sociedad

\footnotetext{
66 Ídem, párr. 527.

67 Ídem, párr. 529-533.

68 El juez recuerda que tales argumentos fueron desestimados en casos como 'Urgenda Foundation v. The State of the Netherlands' y 'WildEarth Guardians v US Bureau of Land Management'.

69 ídem, párr. 539.

70 Ídem, párr. 545.
} 
contemporánea. La constatación de que existen otros proveedores en funcionamiento implicaría que el proyecto no es imprescindible para mantener cubierta la producción global de este bien ${ }^{71}$.

Descartadas las alegaciones del accionante, el juez se dispuso a considerar la cuestión de la viabilidad climática del proyecto. Es aquí donde la resolución cobra mayor interés pues, en un reconocimiento inédito ${ }^{72}$, el magistrado aceptó el enfoque propuesto por la asociación y enmarcó su análisis en la idea del presupuesto de carbono. Específicamente, en una de sus consecuencias lógicas principales: la mayoría de las reservas de combustibles fósiles debe quedar sin explotar ${ }^{73}$.

A partir de aquí, sin embargo, se distanció del razonamiento seguido por la asociación, reformulando las consecuencias de tal situación. Para el juez, el hecho de que 'la mayoría de las reservas de combustibles fósiles deba quedar sin explotar' no implica la prohibición automática de cualquier nuevo proyecto desde que este hecho admite que, en la actualidad y en el corto plazo, ciertas reservas pueden aún ser explotadas. Lo relevante es definir cuáles. La asociación —observó el magistrado—otorga en su razonamiento cierta prioridad a las explotaciones en operación que podrían continuar por, al menos, un breve tiempo. Sin embargo, esta prioridad, si bien lógica, asume que todas las explotaciones en funcionamiento continuarán sin reducciones de emisiones -lo que no debe ser necesariamente así-y, además, advierte el juez, convierte a la resolución en una decisión de política general fuera de su jurisdicción: ningún nuevo desarrollo debería ser aprobado ${ }^{74}$.

Debido a ello, el magistrado afirmó que un enfoque más adecuado consistiría en una evaluación caso por caso de los méritos de cada nuevo proyecto, que incluya

\footnotetext{
71 Ídem, párr. 546-549.

72 En la jurisdicción de Queensland ya se había intentado sin éxito en varios casos encuadrar las evaluaciones de proyectos bajo el enfoque del presupuesto de carbono, incluso mediante la presentación como peritos de prominentes científicos en la materia. Justine Bell-James y Sean Ryan, "Climate Change Litigation in Queensland: A Case Study of Incrementalism", en Environment and Planning Law Journal, Vol. 33, 2016, en referencia a los casos Queensland Land Court, Xstrata Coal Queensland Pty Ltd v. Friends of the Earth - Brisbane Co-Op Ltd, [2012] QLC 13 y Queensland Land Court, Adani Mining Pty Ltd v. Land Services of Coast and Country Inc., [2015] QLC 48.

${ }^{73}$ New South Wales Land and Environmental Court, Gloucester Resources..., cit., párr. 550.

74 Ídem, párr. 551, 552.
} 
la consideración de todas sus emisiones vinculadas y su contraste con el presupuesto de carbono restante. Dicha evaluación, de acuerdo con el juez, podría realizarse en términos absolutos o relativos ${ }^{75}$. En términos absolutos, un proyecto podría, por sí solo, ser una fuente de emisiones suficientemente grande para justificar su rechazo dado el limitado presupuesto de carbono restante ${ }^{76}$. En términos relativos, proyectos de tamaño similar con emisiones similares podrían tener impactos ambientales, sociales y económicos diferentes, los que deberían definir su suerte ${ }^{77}$. Para el caso en cuestión, concluyó el magistrado, los impactos climáticos (emisiones directas e indirectas) constituyen una razón extra a los inaceptables impactos de planificación, visuales y sociales que justifican la denegatoria del consentimiento al proyecto ${ }^{78}$.

\section{Resolución}

El juez se inclinó entonces por denegar el consentimiento, observando que, tanto en perspectiva intra como intergeneracional ${ }^{79}$, los impactos negativos del proyecto, incluyendo aquellos sobre el sistema climático, superaban los positivos $^{80}$. De este modo, una corte australiana denegó, por primera vez, la autorización a un proyecto minero debido (aunque parcialmente) a sus impactos climáticos ${ }^{81}$.

En un extracto de la resolución que será muy repetido, el juez resumió su sentencia manifestando que el proyecto fue concebido en el lugar equivocado, en el momento equivocado:

In short, an open cut coal mine in this part of the Gloucester valley would be in the wrong place at the wrong time. Wrong place because an open cut coal mine in this scenic and cultural landscape, proximate to many people's homes and farms, will cause significant planning, amenity, visual and social impacts. Wrong time because the GHG emissions of the coal mine and its coal product will increase global total concentrations of GHGs at a time when

\footnotetext{
75 Ídem, párr. 553.

76 Ídem, párr. 554.

77 ídem, párr. 555.

78 Ídem, párr. 556.

79 Ídem, párr. 697.

80 Ídem, párr. 668.

${ }^{81}$ Robert White, Jemilah Hallinan y Belinda Rayment, "Climate Change Takes Centre Stage in Land and Environment Court", en Law Society of NSW Journal, núm. 54, 2019, p. 80-82.
} 
what is now urgently needed, in order to meet generally agreed climate targets, is a rapid and deep decrease in GHG emissions ${ }^{82}$.

\section{DISCUSIÓN: LA RELEVANCIA DEL CASO}

La resolución del juez Preston se convirtió en la decisión definitiva sobre la cuestión desde que el accionante decidió no recurrir su legalidad ${ }^{83}$ y abandonar el proyecto ${ }^{84}$. Más allá de esta repercusión inmediata, el fallo afectó rápidamente el panorama de autorización de proyectos similares en la región, lo que desató una igualmente veloz reacción por parte de grupos interesados y del gobierno local. Teniendo en cuenta esto y dado que la evaluación de los impactos ambientales previa a la autorización de proyectos es una práctica universalmente extendida $^{85}$, conviene iniciar una discusión sobre la relevancia del caso y, específicamente, del enfoque del presupuesto de carbono acogido por el juez ${ }^{86}$.

\section{Integración de los límites planetarios en la toma de decisiones}

Una primera reflexión de carácter general surge a partir de la apreciación con la que el juez cierra su sentencia: el proyecto fue concebido, no solo en un 'lugar equivocado', sino en un 'momento equivocado' en el que lo urgente es la

82 Ídem, párr. 699.

83 Jerome Doraisamy, "No appeal filed against 'groundbreaking' climate change judgment", LawyersWeekly, 10 de mayo de 2019, <https://www.lawyersweekly.com.au/wig-chamber/25613no-appeal-filed-against-groundbreaking-climate-change-judgment> [última consulta, 7 de octubre de 2019]

${ }^{84}$ Rocky Hill Coal Project, "Rocky Hill Coal Project will not proceed", 8 de mayo de 2019, $<$ https://www.rockyhillproject.com.au/2019/05/rocky-hill-coal-project-will-not-proceed/> [última consulta, 7 de octubre de 2019]

85 A 2017, existían instrumentos jurídicos solicitando evaluaciones ambientales para la aprobación de proyectos en 187 países. United Nations Environment Programme, "Environmental Rule of Law: First Global Report", 2019, p. 2, $<$ https://wedocs.unep.org/bitstream/handle/20.500.11822/27279/Environmental_rule_of_law.pdf ?sequence $=1$ \&isAllowed $=\mathrm{y}>$ [última consulta, 14 de enero de 2020]

86 Como el precedente 'Urgenda' ha demostrado, la transmisibilidad de estrategias y argumentaciones jurídicas de una jurisdicción a otra, aún en contextos fácticos similares, puede ser compleja. Al respecto véase por ejemplo: Roger Cox, "The Liability of European States for Climate Change", en Utrecht Journal of International and European Law, Vol. 125, núm. 30, 2014; sobre las dificultades y perspectivas de reproducción en el contexto español: Jordi Jaria i Manzano, "La litigació climática a Espanya: una prospectiva", en Revista Catalana de Dret Ambiental, Vol. 9, núm. 2, 2018; Albert Ruda-Gonzalez, "Perspectives de la litigació pel canvi climàtic arran del cas Urgenda", en Revista Catalana de Dret Ambiental, Vol. 9, núm. 2, 2018. 
reducción de las emisiones ${ }^{87}$. Este 'momento' no es otra cosa que el 'estado de emergencia' en el que ha entrado el Sistema Tierra a raíz de la amenaza de un aumento incontrolado de la temperatura ${ }^{88}$. Emergencia que, por su parte, ha sido reconocida en diversas declaraciones políticas ${ }^{89}$.

Es posible argumentar que en este 'estado de emergencia' urge, más que nunca, la internalización de los límites físicos del Sistema Tierra en la toma de decisiones presumiblemente disruptivas ${ }^{90}$. En este sentido, dentro del marco ya consolidado de la evaluación de impactos ambientales, el enfoque del presupuesto de carbono cumpliría al menos parte de esta tarea al ofrecer un parámetro, científicamente sólido, para la evaluación de los impactos acumulativos sobre el sistema climático de determinadas decisiones de planeamiento ${ }^{91}$.

Según la resolución analizada, un examen bajo este enfoque tendría entidad suficiente como para condicionar 0 incluso denegar válidamente el consentimiento al desarrollo de un determinado proyecto, debido a la inaceptabilidad de sus emisiones previsibles con respecto al escaso presupuesto de carbono global restante. De esta forma, podría constituirse en un mecanismo útil a la hora de garantizar, aunque sea parcialmente, que las acciones propuestas se mantengan dentro de ciertos límites planetarios ${ }^{92}$.

\footnotetext{
87 Véase Chris Hilson, "Framing Time in Climate Change Litigation", en Oñati Socio-legal Series, Vol. 9, núm. 3, 2019, p. 361-379.

88 Will Steffen et al., "Trajectories of the Earth System in the Anthropocene", en Proceedings of the National Academy of Sciences, Vol. 113, núm. 33, 2018.

89 Por ejemplo en España, Consejo de Ministros, Referencia 21 de enero de 2020, Acuerdo por el que se aprueba la declaración del Gobierno ante la emergencia climática y ambiental, $<$ https://www.lamoncloa.gob.es/consejodeministros/referencias/documents/2020/refc20200121. pdf> [última consulta, 25 de mayo de 2020]; y a nivel regional, Parlamento Europeo, "European Parliament resolution of 28 November 2019 on the climate and environment emergency (2019/2930(RSP)", $<$ http://www.europarl.europa.eu/doceo/document/TA-9-20190078_EN.html> [última consulta, 1 de diciembre de 2019]

90 Véase Antonio Cardesa-Salzmann y Endrius Cocciolo, "Global Governance, Sustainability and the Earth System: Critical Reflections on the Role of Global Law", en Transnational Environmental Law, Vol. 8, núm. 3, 2019, p. 437-461.

${ }^{91}$ Michael Gerrard, "Council on Environmental Quality Declares that Climate Change Is Already Covered in Environmental Impact Review, and No New Regulation Is Needed", Climate Law Blog, 13 de agosto de 2014, <http://blogs.law.columbia.edu/climatechange/2014/08/13/council-onenvironmental-quality-declares-that-climate-change-is-already-covered-in-environmentalimpact-review-and-no-new-regulations-needed/> [última consulta, 25 de mayo de 2020]

92 Johan Rockström et al., "Planetary Boundaries: Exploring the Safe Operating Space for Humanity", en Ecology and Society, Vol. 14, núm. 2, 2009.
} 
Debe notarse que, desde una perspectiva lógica, la implementación de este enfoque es, por un lado, extensible globalmente atento al carácter compartido del presupuesto -es decir podría ser alegable en casi cualquier jurisdicción ${ }^{93}$ y, por otro lado, de carácter progresivo, en el sentido de que a medida que el presupuesto de carbono se agote también lo debería hacer el margen de discrecionalidad administrativa para la aprobación de ciertos proyectos.

Hechas estas consideraciones generales, conviene observar cuáles han sido las efectivas repercusiones de esta resolución judicial (y su utilización de este enfoque) en el panorama local, como así también especular sobre su posible incidencia fuera de este ámbito.

\section{Relevancia del caso como precedente para la toma de decisiones de planeamiento}

Es posible afirmar que la resolución del juez Preston se convirtió rápidamente en un punto de inflexión en lo que hace a la práctica decisoria administrativa local sobre aprobación de minas de carbón. Mientras que era previsible que actores de la sociedad civil comenzaran a solicitar a la administración de planeamiento que evalúe todo nuevo proyecto bajo los parámetros delineados por la sentencia ${ }^{94}$, la IPC ya efectivamente hizo esto en al menos tres casos con consecuencias relevantes para su definición.

En agosto de 2019, la autoridad aprobó la reapertura de una mina de carbón Dartbrook Coal Mine - hasta 2022, pero denegó su extensión hasta 2027 como había solicitado el promotor, alegando que las emisiones de GEI no habían sido adecuadamente consideradas en la solicitud de extensión y mencionando expresamente la resolución aquí analizada ${ }^{95}$. Ese mismo mes, la autoridad dio

\footnotetext{
${ }_{93} \mathrm{Al}$ menos en aquellas en que se ha ratificado el Acuerdo de París por el que se cuantificó el presupuesto.

${ }_{94}$ Louise Nichols, "Friends of the Upper Hunter want Dartbrook project evaluated in light of Rocky Hill ruling", The Singleton Argus, 9 de mayo de 2019, $<$ https://www.singletonargus.com.au/story/6114584/no-appeal-on-rocky-hill-decision/> [última consulta, 7 de octubre de 2019]

${ }^{95}$ New South Wales Government, Independent Planning Commission, "Statement of reasons for decision", 9 de agosto de 2019, párr. 129 y 243, $<$ https://www.ipcn.nsw.gov.au/resources/pac/media/files/pac/projects/2019/02/dartbrook-coalmine-modification-7/determination/dartbrook-coal-mine-mod-7--statement-of-reasons-fordecision.pdf> [última consulta, 11 de febrero de 2020]
} 
consentimiento a la expansión de una mina de carbón —United Wambo Coal Project - pero, de manera inédita, aludiendo al caso aquí analizado y al presupuesto de carbono, estableció la condición de que todo el carbón sea exportado a países que hayan ratificado el Acuerdo de París o que tengan políticas de reducción de emisiones ${ }^{96}$. Por su parte, más destacable aún, en septiembre 2019 la autoridad denegó autorización a la apertura de una mina de carbón -Bylon Coal Project-, utilizando expresamente muchos de los argumentos -incluido el enfoque del presupuesto de carbono- acogidos por el magistrado en el caso bajo análisis ${ }^{97}$.

Esto parece señalar que la sentencia ha impulsado a la autoridad administrativa a dar el paso de denegar o condicionar el consentimiento a proyectos debido, aunque sea parcialmente, a sus contribuciones al cambio climático. Al menos parte de este impulso, presumiblemente, esté relacionado al resguardo legal que la sentencia significa para la autoridad. Seguir los considerandos del tribunal le asegura, en principio, cierta validez jurídica de su decisión frente a posibles impugnaciones.

Sin embargo, este resguardo se limita, en todo caso, al plano jurídico y no político. El gobierno regional, considerando las implicancias de la resolución en el panorama de planeamiento local e impulsado por la preocupación del sector minero, promovió dos polémicas medidas en reacción. Por un lado, instó una revisión del órgano de planeamiento independiente (IPC) $)^{98}$-incluyendo un

\footnotetext{
${ }^{96}$ Amelia Bernasconi, "United Wambo open cut coal 'super pit' approved for NSW Hunter Valley with export conditions", $A B C, 30$ de agosto de 2019, <https://www.abc.net.au/news/2019-0829/united-wambo-approved-with-paris-climate-agreement-conditions/11460970> [última consulta, 7 de octubre de 2019]; New South Wales Government, Independent Planning Commission, "Statement of reasons for decision", 29 de agosto de 2019, párr. 298, $<$ https://www.ipcn.nsw.gov.au/resources/pac/media/files/pac/projects/2018/11/united-wamboopen-cut-coal-mine-project-ssd-7142/determination/uwjv--sor--final.pdf> [última consulta, 7 de octubre de 2019]

97 Lisa Cox, "Massive Bylong valley coalmine in NSW blocked on environmental grounds", The Guardian, 18 de septiembre de 2019, <https://www.theguardian.com/australianews/2019/sep/18/massive-bylong-coalmine-in-nsw-blocked-on-environmental-

grounds?CMP=share_btn_link> [última consulta, 2 de diciembre de 2019]; New South Wales Government, Independent Planning Commission, "Statement of reasons for decision", 18 de septiembre de

2019 <https://www.ipcn.nsw.gov.au/resources/pac/media/files/pac/projects/2018/10/bylong-coalproject/determination/bylong-coal-project-ssd-6367--statement-of-reasons-for-decision.pdf> [última consulta, 2 de diciembre de 2019]

${ }_{98}$ Christopher Knaus, "NSW Minerals Council pressured 'publicly and privately' for review of planning body", The Guardian, 21 de octubre de 2019, <https://www.theguardian.com/australia-
} 
estudio del interés de su propia existencia99- que finalmente acabó restringiendo su ámbito de actuación ${ }^{100}$. Por otro, impulsó legislación para impedir que las autoridades de planeamiento puedan denegar o condicionar el consentimiento a proyectos debido al impacto climático de las emisiones que se producen fuera del territorio australiano con la quema del producto ${ }^{101}$. Al respecto, el ministro de industria regional fue elocuente al manifestar que estos cambios ayudarían a restaurar la ley y políticas del Estado a la situación que existía con anterioridad a la decisión del juez Preston, proveyendo certeza al sector minero ${ }^{102}$.

La toma de medidas políticas en respuesta a procesos jurisdiccionales que de algún modo limitan el desarrollo de proyectos de minería de carbón por

news/2019/oct/21/nsw-minerals-council-pressured-publicly-and-privately-for-review-of-planningbody> [última consulta, 25 de noviembre de 2019]

99 Commissioner for Productivity, "Terms of Reference, Review of Independent Planning Commission", $<$ http://productivity.nsw.gov.au/sites/default/files/201910/IPC\%20Review\%20Terms\%20of\%20Reference.pdf> [última consulta, 25 de noviembre de 2019]

100 Por ejemplo, mientras que antes tenía competencia sobre proyectos contra los que se habían presentado, al menos, 25 objeciones por parte del público, con la reforma este requerimiento se ha elevado a 50 objeciones. Julie Power, "Independent Planning Commission to be final arbiter only on state's most contentious projects", The Sydney Morning Herald, 1 de febrero de 2020, $<$ https://www.smh.com.au/politics/nsw/independent-planning-commission-to-be-final-arbiter-ononly-state-s-most-contentious-projects-20200201-p53wsx.html> [última consulta, 11 de febrero de 2020]; New South Wales Government, Independent Planing Commission, "Review of Independent Planning Commission", <https://www.ipcn.nsw.gov.au/review-of-commission> [última consulta, 25 de mayo de 2020]

101 Lisa Cox, "NSW considers laws to stop courts and planners blocking coalmines on climate grounds", The Guardian, 1 de octubre de 2019, $<$ https://www.theguardian.com/environment/2019/oct/02/nsw-considers-laws-to-stop-courts-

and-planners-blocking-coalmines-on-climate-grounds> [última consulta, 7 de octubre de 2019]; Lisa Cox, "NSW moves to stop mine projects being blocked because of their overseas emissions", The Guardian, 22 de octubre de 2019, $<$ https://www.theguardian.com/environment/2019/oct/22/nsw-to-try-to-stop-mine-projects-beingblocked-because-of-their-overseas-emissions?CMP=twt_a-environment_b-gdneco> [última consulta, 22 de octubre de 2019]; New South Wales, "Environmental Planning and Assessment Amendment (Territorial Limits) Bill 2019", <https://www.parliament.nsw.gov.au/bill/files/3717/First\%20Print.pdf> [última consulta, 11 de febrero de 2020]; Al momento de escribir, la propuesta se encuentra en examen parlamentario, habiéndose recomendado su no aprobación en su redacción actual. Parliament of New South Wales, Environmntal Planning and Assessment Amendment (Territorial Limits) Bill 2019, $<$ https://www.parliament.nsw.gov.au/bills/Pages/bill-details.aspx?pk=3717> [última consulta, 26 d mayo de 2020]

102 Cox, "NSW moves to stop mine...", cit; Por su parte, la Administración Trump en Estados Unidos parece querer recorrer el mismo camino intentando reformar la aplicación de la National Environmental Policy Act; Lisa Friedman, "Trump Rule Would Exclude Climate Change in Infrastructure Planning", The New York Times, 3 de enero de 2020 < https://www.nytimes.com/2020/01/03/climate/trump-nepa-climate-change.html> [última consulta, 8 de abril de 2020] 
cuestiones climáticas no es un hecho nuevo en Australia, con antecedentes especialmente interesantes en la jurisdicción de Queensland ${ }^{103}$. Este tipo de medidas -que evidencian el carbon entanglement en el que se encuentran sumergidos algunos gobiernos- pueden, sin embargo, tener costos políticos no despreciables, los que aumentarán en la medida en que lo haga la preocupación social por la problemática climática ${ }^{104}$.

Al momento de considerar si pueden esperarse decisiones administrativas similares en otros contextos normativos, esta reacción política debe tenerse presente. En este sentido, es evidente que la independencia funcional que caracteriza al órgano administrativo actuante (IPC) fue un elemento clave sin el cual difícilmente la resolución del tribunal hubiese logrado tanto impacto en un período tan corto de tiempo. Esta independencia, debe notarse, es una particularidad no fácilmente repetible en órganos de planeamiento en otras jurisdicciones.

No obstante ello, no debería descartarse de plano la posibilidad de que el caso (y su consideración del presupuesto de carbono) pueda inspirar -a modo de buenas prácticas- a autoridades administrativas de otras jurisdicciones en la forma de considerar los impactos acumulativos sobre el sistema climático de proyectos. En este sentido, un examen más estricto en el otorgamiento de autorizaciones a proyectos de alto impacto climático debiese ser esperable, al menos, en estados desarrollados que han asumido tomar el liderazgo frente a la problemática del cambio climático y que han declarado y reconocido el estado de emergencia con el objetivo de comprometer futuras políticas de gobierno.

Asimismo, siguiendo a Green, podría entenderse el caso como un paso más hacia la construcción de una norma moral de carácter global contraria a la proliferación de nuevas extracciones de combustibles fósiles, con la capacidad

103 Jaqueline Peel y Hari Osofsky, Climate Change Litigation: Regulatory Pathways to Cleaner Energy, Cambridge University Press, 2015, p. 301, 302; en referencia a la sentencia Queensland Court of Appeal, Queensland Conservation Council Inc v. Xstrata Coal Queensland P/L \& Ors, [2007] QCA 338, sentencia del 12 de octubre de 2007.

104 Bell-James y Ryan, "Climate Change Litigation...., cit., p. 536, “...while there is an argument that climate change litigation can negatively impact on legislative change, there is equally an argument that doing so is politically unpopular due to the large public support for climate change action." 
de afectar el comportamiento de los actores más relevantes (estados y corporaciones) ${ }^{105}$. En el enfoque planteado por este autor, la asociación civil que intervino en el proceso habría actuado como norm entrepreneur, impulsando la aplicación de un nuevo estándar, y el tribunal como norm champion, mediante la adopción temprana y la promoción del nuevo estándar ${ }^{106}$. En este entendimiento, el caso llamaría a prestar debida atención al rol de la litigación y los tribunales en la construcción de este tipo de norma, considerando sus efectos de retroalimentación positivos, pero también aquellos negativos señalados ${ }^{107}$.

Dicho esto, debe notarse que fuera del contexto jurídico del caso, otras administraciones que diesen estos pasos no contarían, en principio, con el resguardo legal que otorga esta resolución a la autoridad australiana, pudiendo quedar expuestas a litigios en tutela de intereses económicos de los promotores ${ }^{108}$. En este sentido, interesa indagar sobre la posible recepción judicial del enfoque.

\section{Relevancia del caso como precedente judicial}

Dada la particular naturaleza de la jurisdicción ejercida por el tribunal en el caso, conviene hacer alusión a su posible relevancia para futuras causas en que se dé intervención a los poderes judiciales, ahora sí, en su clásica función de control de legalidad. Respecto a ello, en lo que hace al ámbito jurídico del caso, deben diferenciarse dos supuestos. Por un lado, la relevancia del fallo como precedente ante cuestionamientos judiciales de decisiones administrativas denegatorias de nuevos proyectos (típicamente impulsados por los promotores). Por otro, su relevancia ante futuros cuestionamientos judiciales de decisiones administrativas favorables a la aprobación nuevos proyectos (típicamente promovidos por asociaciones civiles con fines ambientales).

\footnotetext{
${ }^{105}$ Fergus Green, “Anti Fossil-fuel Norms”, en Climatic Change, Vol. 150, 2018.

106 Ídem, p. 105.

107 Ídem, p. 106.

108 Veáse England and Wales High Court (Administrative Court), H J Banks \& Company Ltd. v. Secretary of State for Housing Communities and Local Government, et al., [2018] EWHC 3141 (Admin), sentencia del 23 de noviembre de 2018, donde el tribunal revocó la decisión de la autoridad administrativa de denegar el permiso para una mina de carbón debido a sus impactos climáticos.
} 
Con respecto al primer supuesto, como ya se mencionó, es posible asumir que la sentencia está cumpliendo una función de resguardo legal —más allá de su naturaleza particular - para con las decisiones de la autoridad de planeamiento que sigan los parámetros dispuestos por el juez. Esto tiene que ver, al menos, (a) con el rol que la legislación otorga a este tribunal en el control de legalidad de los procesos de planeamiento de este tipo de infraestructura ${ }^{109}$, (b) con el hecho de que la resolución haya quedado firme ${ }^{110}$ y (c) con cierta autoridad argumentativa que se le ha reconocido a la misma ${ }^{111}$. Hasta cierto punto, pronto podrá confirmarse o desecharse esta asunción cuando la NSWLEC resuelva la apelación interpuesta a la denegatoria del Bylong Coal Project. El tribunal actuará en este caso en revisión de legalidad de la decisión de la IPC ${ }^{112}$.

Con respecto al segundo supuesto, si alguien podía imaginar que el fallo representaría el principio de muchas impugnaciones judiciales sobre aprobaciones de nuevas minas de carbón, es necesario decir que esto ya fue, en cierta medida, descartado por el propio tribunal. Poco más de un mes después del caso de Rocky Hill, el tribunal (ahora, juez Tim Moore) volvió a expedirse sobre el consentimiento de un proyecto de mina de carbón -Wallarah 2 Coal Project-, pero, en este caso, en control de legalidad de la aprobación del proyecto por la autoridad administrativa ${ }^{113}$. El accionante planteó que la autoridad no había tenido debidamente en cuenta, entre otras cosas, las emisiones Scope 3, según los parámetros del precedente 'Gloucester'. Sin embargo, el tribunal, remarcando las diferencias entre la revisión de mérito y de legalidad ${ }^{114}$, entendió que la decisión —a pesar de no seguir el razonamiento del

\footnotetext{
109 Véase nota 42 supra.

110 Véase nota 83 supra.

111 Lesley Hughes, "The Rocky Hill Decision: A Watershed for climate change action?", en Journal of Energy \& Natural Resources Law, Vol. 37, núm. 3, 2019, p. 9; New South Wales Government, Independent Planning Commission, "Statement of reasons...", 29 de agosto de 2019, cit., párr. 283.

112Joanne McCarthy, "Korean Government-backed KEPCO is taking the only appeal path available to recover $\$ 750 \mathrm{~m}$ Bylong mine investment", Newcastle Herald, $<$ https://www.newcastleherald.com.au/story/6547840/korean-energy-company-kepco-seeksjudicial-review-of-landmark-bylong-coal-mine-refusal/> [última consulta, 26 de mayo de 2020] 113 New South Wales Land and Environmental Court, Australian Coal Alliance Incorporated $v$ Wyong Coal Pty Ltd [2019] NSWLEC 31, sentencia del 22 de marzo de 2019.

114 Sobre diferencias entre casos de litigación climática bajo una u otra jurisdicción, véase Brian Preston, "Mapping Climate Change Litigation”, en Australian Law Journal, Vol. 92, 2018.
} 
precedente - no implicaba ilegalidad manifiesta alguna que permitiese impugnar el consentimiento ${ }^{115}$.

En lo que aquí compete, esto parece implicar que, de acuerdo con el estado actual de la jurisprudencia local, el enfoque del presupuesto de carbono debe entenderse como un parámetro del cual puede servirse válidamente la autoridad de planeamiento, pero no como requisito legal de obligada utilización. Esto condice con el desarrollo jurisprudencial en la jurisdicción más prolífera de la litigación climática ${ }^{116}$. En al menos dos casos, tribunales estadounidenses han descartado que la no utilización del enfoque del presupuesto de carbono pueda tornar arbitraria o caprichosa la valoración de la autoridad y, consecuentemente, constituir una infracción a la ley ${ }^{117}$. Al menos en un puñado más de casos, por el momento sin resolución, se ha insistido en la aplicación de este y otros parámetros para la evaluación de la magnitud de los impactos climáticos acumulativos de determinadas decisiones ${ }^{118}$.

Establecido esto, es necesario plantear dos cuestiones. Por un lado, sería un error afirmar livianamente que todos y cada uno de los estándares reconocidos por el juez Preston en su sentencia encuentran limitada su trascendencia a

\footnotetext{
115 New South Wales Land and Environmental Court, Australian Coal..., cit., párr. 41. El tribunal incluso manifiesta expresamente que no comparte el proceder de la administración que, debe aclararse, había actuado previamente a la resolución de Rocky Hill.

116 Véase Michael Burger y Jessica Wentz, "Evaluating the Effects of Fossil Fuel Supply Projects on Greenhouse Gas Emissions and Climate Change Under NEPA", en William \& Mary Environmental Law and Policy Review, Vol. 44, 2020, p. 423-529.

117 United States District Court for the District of Montana Great Falls Division, Western Organization of Resource Councils, et al. v. U.S. Bureau of Land Management, et al., CV 16-21GF-BMM, sentencia del 26 de marzo de 2018; United States District Court for the District of Columbia, WildEarth Guardians, et al. v. Zinke, et al., 16-1724(RC), sentencia del 19 de marzo de 2019, p. 49, 50. Para los tribunales es suficiente la evaluación de las emisiones del proyecto como porcentaje de las generadas a nivel estatal o nacional. En el último, los demandantes han vuelto a plantear una demanda alegando nuevas fallas a las evaluaciones, afirmando que, esta ve, la autoridad sí utilizó el enfoque del presupuesto de carbono (algo que al parecer cuestionará la propia autoridad) pero que lo hizo de manera inconsistente, irracional y arbitraria, por lo que pretende que el tribunal discuta sobre la manera apropiada de su aplicación y de sus resultados. United States District Court for the District of Columbia, WildEarth Guardians..., cit., moción para sentencia sumaria del 6 de enero de 2020.

118 United States District Court for the District of Alaska, Alaska Wilderness League, et al. v. Sally Jewell et al., Case No. 1:08-cv-00004-RRB, memoria inicial de los demandantes del 28 de agosto de 2015, p. 30 sobre producción de petróleo y gas en el mar de Chukchi. Los litigantes manifiestan que la falla de la autoridad en evaluar las concesiones y sus potenciales impactos climáticos bajo el enfoque del presupuesto de carbono global viola los requisitos de la ley de planeamiento ambiental (NEPA); United States District Court fo the District of Colorado, Wilderness Workshop, et al. v. U.S. Bureau of Land Management, et al., Case No. 1:18-cv-00987, demanda, 26 de abril de 2018.
} 
entenderse como 'buenas prácticas' con validez legal. Por el contrario, es posible pensar que algunos de ellos afectarán el control de legalidad de futuros casos. Esto es así, por ejemplo, con respecto al entendimiento de que las emisiones indirectas, incluso producidas fuera del territorio nacional, y acumulativas de un proyecto son relevantes a los fines de la toma de decisiones, como también con respecto a la existencia de un nexo causal entre un proyecto determinado y los impactos derivados del cambio climático. Estos estándares han sido fundamentados por el magistrado mediante disposiciones normativas, principios jurídicos ampliamente aceptados (principio de precaución y de equidad intergeneracional) y jurisprudencia local y comparada, por lo que su valor excede el de posibles 'buenas prácticas administrativas'. Lo mismo sucede en torno a la impugnación de los argumentos del 'market substitution' y el 'carbon leakage', responsables, en gran medida, de la suerte de muchos litigios en jurisdicción australiana $^{119}$. Con respecto a esto, la sentencia se suma a algún otro precedente y a alegaciones doctrinales que se expresan en favor del abandono de tal argumentación en sede administrativa y judicial ${ }^{120}$.

Por otro lado, es posible indagar sobre una posible evolución de la jurisprudencia en torno a dos cuestiones. La primera, relativa al requerimiento legal de la utilización de parámetros para la adecuada valoración de los impactos acumulativos sobre el sistema climático de una acción. La segunda relativa a la necesidad legal de que el parámetro elegido sea el del presupuesto de carbono. Con respecto a la primera cuestión, puede argumentarse que, una vez reconocida la necesidad de considerar los impactos acumulativos climáticos del proyecto, la autoridad debe utilizar algún criterio disponible para tal consideración ${ }^{121}$. Con respecto a la segunda, podría ser posible argüir que tal

\footnotetext{
119 Véase al respecto, Bell-James y Ryan, "Climate Change Litigation...", cit.

120 United States Court of Appeals, $10^{\text {th }}$ Circuit, WildEarth Guardians et al. v. U.S. Bureau of Land Management et al., Case No. 15-8109, sentencia del 15 de septiembre de 2017, p 29: "...we hold that it was an abuse of discretion to rely on an economic assumption, which contradicted basic economic principles, as the basis for distinguishing between the no action alternative and the preferred alternative". Justine Bell-James y Brianna Collins, "If We Don't Mine Coal, Someone Else Will": Debunking the "Market Substitution Assumption" in Queensland Climate Change Litigation", en Environmental and Planning Law Journal, Vol. 37, núm. 2, 2020, rebatiendo la market substitution theory y cuestionando su adopción judicial

${ }^{121}$ Burger y Wentz, "Evaluating the Effects of Fossil Fuel Supply Projects...", cit., p. 481, en referencia al caso United States District Court for the District of Montana Great Falls Division, Western Organization of Resource Councils..., cit.
} 
enfoque es una forma, científicamente sólida, de concretar las metas acordadas en el acuerdo de París ${ }^{122}$. Como sea, parece claro que este será un camino por recorrer para la jurisprudencia climática transnacional, sobre el cual el precedente aquí analizado aporta sus primeros fundamentos.

El reconocimiento de autoridad argumentativa (persuasive authority) ${ }^{123}$ que se ha atribuido a la sentencia es un factor relevante a la hora de especular sobre sus impactos fuera del propio contexto jurídico, donde en buena medida las suspicacias producto de su especial naturaleza (de mérito) se diluyen. Así, podría decirse que el fallo tiene potencialidad para ser fuente de inspiración y argumentación en otras sedes judiciales, sobre todo considerando la retroalimentación existente entre tribunales en materia de litigación climática ${ }^{124}$ y, más general, el carácter de diálogo regulatorio transnacional que se le ha reconocido a este fenómeno ${ }^{125}$.

\section{Aplicación del enfoque del presupuesto de carbono}

Si se presume que el enfoque del presupuesto de carbono puede ser objeto de un paso próximo de la jurisprudencia climática, interesa indagar sobre su forma de aplicación. Esta será, en definitiva, parte de la materia a controlar por los tribunales.

En cuanto a esto, lo primero que debe decirse es que es condición de partida que las evaluaciones ambientales incluyan y analicen adecuadamente las emisiones de GEI de los proyectos propuestos ${ }^{126}$, algo que alguna legislación

\footnotetext{
122 Jaqueline Peel, Hari Osofsky y Anita Foerster, "A 'Next Generation' of Climate Change Litigation?: an Australian Perspective", en Oñati Socio-Legal Series, Vol. 9, núm. 3, 2019, p. 283, 284.

123 En contraposición a binding authority. Véase nota 111 supra.

${ }^{124}$ Fuertemente expresado en las referencias de la resolución analizada y en otros casos como 'Juliana v. USA' o 'Futuras Generaciones v. Ministerio de Ambiente de Colombia y ots.'; United States District Court for the District of Oregon Eugene Division, Kelsey Cascadia Rose Juliana, et. al. v. United States of America, et. al., Case No. 6:15-cv-01517-TC, sentencia del 10 de noviembre de 2016; Corte Suprema de Justicia de Colombia (Sala de Casación Civil), Futuras Generaciones v. Presidencia de la República de Colombia, STC4360-2018, sentencia del 5 de abril de 2018.

125 Jaqueline Peel y Jolene Lin, "Transnational Climate Litigation: The Contribution of the Global South", en American Journal of International Law, Vol. 113, núm. 4, 2019, p. 70.

126 Véase Stephen Russell, "A Recommended Methodology for Estimating and Reporting the Potential Greenhouse Gas Emissions from Fossil Fuel Reserves", World Resources Institute,
} 
nacional prevé ${ }^{127}$ pero que no es una práctica tan extendida ${ }^{128}$. Sobre este punto, creciente jurisprudencia, dentro de la que se cuenta este precedente, señala en la dirección de que la inclusión de los impactos climáticos en las evaluaciones ambientales es, más que una simple tendencia regulatoria, un requisito legal de carácter procesal ${ }^{129}$. Para el caso de proyectos de producción de combustibles fósiles, a su vez, es fundamental la consideración de las emisiones indirectas (producto de la quema del combustible) para definir como significativos sus impactos previstos, algo que la litigación en NSW logró promover como requisito ${ }^{130}$. Además, resulta relevante que las emisiones del proyecto sean cuantificadas en forma acumulativa y no en base a emisiones anuales, pues a los fines del agotamiento del presupuesto, es el total de las emisiones acumuladas a lo largo de la vida del proyecto lo que realmente importa ${ }^{131}$.

En segundo lugar, en cuanto a la aplicación del enfoque en sí, debe notarse que la resolución analizada no dice mucho al respecto. Solo manifiesta que, en un

Working Paper, 2016, p.1, <https://wriorg.s3.amazonaws.com/s3fspublic/A_Recommended_Methodology_for_Estimating_and_Reporting_the_Potential_Greenho use_Gas_Emissions_from_Fossil_Fuel_Reserves.pdf> [última consulta, 11 de febrero de 2020] 127 Es el caso de España: Ley 21/2013, de 9 de diciembre, de evaluación ambiental, España, 11 de diciembre de 2013, Boletín Oficial del Estado; y en el marco europeo: Directiva 2014/52/UE del Parlamento Europeo y del Consejo, de 16 de abril de 2014, por la que se modifica la Directiva 2011/92/UE, relativa a la evaluación de las repercusiones de determinados proyectos públicos y privados sobre el medio ambiente, Unión Europea, 25 de abril de 2015, Diario Oficial de la Unión Europea.

128 Del análisis de Enríquez de Salamanca Sánchez-Cámara sobre la situación global se extrae que, si bien existe normativa que lo contempla, su implementación es defectuosa y dispar; Álvaro Enríquez de Salamanca Sánchez-Cámara, Consideración del cambio climático en la evaluación de impacto ambiental de infraestructuras lineales de transporte, Tesis, Universidad Nacional de Educación a Distancia (España), 2017, p. 39 y ss.

129 Véase, por ejemplo, High Court of South Africa, Gauteng Division, Pretoria, Earthlife Africa Johannesburg v. The Minister of Environmental Affairs et. al., Case No.: 65662/16, sentencia del 8 de marzo de 2017; New South West Land and Environment Court, Gray v. The Minister of Planning and Ors, Case No.: 40870/2006, sentencia del 27 de noviembre de 2006; United States Court of Appeals, $9^{\text {th }}$ Circuit, Center for Biological Diversity v. National Highway Traffic Safety Administration, 508 F.3d 508, sentencia del 15 de noviembre de 2007; Peel y Osofsky, "Climate Change Litigation...", cit., p. 72. En contraposición, véase dos sentencias del Tercer Tribunal Ambiental de Chile. Tercer Tribunal Ambiental de Chile, Corporación Privada para el Desarrollo de Aysén y ots. v. Comité de Ministros, R 42-2016, sentencia del 4 de enero de 2018, p. 33829, 33830 , donde el tribunal manifiesta que el ámbito de evaluación ambiental previsto en la legislación es solo local y, por lo tanto, no hay obligación de considerar cuestiones relativas al cambio climático. "Desde luego es deseable que la Administración tenga en cuenta los efectos positivos y negativos que puede provocar un proyecto en el manejo del cambio climático, pero la Ley actual no obliga a tenerlo en cuenta". Tercer Tribunal Ambiental de Chile, Simonetti Grez, Gabriela y ots. v. Servicios de Evaluación Ambiental, R 77-2018, sentencia del 20 de agosto de 2019, p. $22155-22158$.

130 Peel y Osofsky, "Climate Change Litigation...", cit., p. 99.

${ }^{131}$ Bell-James y Ryan, "Climate Change Litigation...", cit., p. 533. 
análisis caso por caso, un proyecto podría ser rechazado en términos absolutos, es decir exclusivamente por la inaceptabilidad de sus emisiones con respecto al presupuesto de carbono global, o en términos relativos, es decir como motivación extra a otros impactos significativos. De hecho, si se toman como referencia las resoluciones de la IPC posteriores a la sentencia, debe notarse que, utilizando los argumentos del juez, llegó a resoluciones disímiles. En definitiva, existe cierto riesgo de caer en una aplicación poco significativa o arbitraria del enfoque, pues no está del todo claro cuándo un proyecto implicaría emisiones de suficiente magnitud para considerarse inadmisible, en tanto que no existe o al menos no surge del fallo un parámetro claramente discernible.

En el campo propositivo, es posible plantear para futura discusión algunos criterios que podrían desarrollar este enfoque. Una primera opción implicaría volver sobre la mencionada consecuencia del análisis del presupuesto de carbono restante: la mayoría de las reservas de combustibles fósiles debe quedar sin explotar. Sobre esto, no puede olvidarse la advertencia que hace el magistrado en su resolución: la prohibición total de nuevas fuentes es, por un lado, no necesariamente la única conclusión lógica de este análisis, y por otro, una determinación general que corresponde realizar en otro nivel de toma de decisión. Ahora bien, podría plantearse que una consideración seria ${ }^{132}$ de esta premisa (escasez del presupuesto) debe llevar racionalmente al entendimiento de que la aprobación de nueva infraestructura fósil puede ser solo estrictamente excepcional. Aplicar el enfoque consistiría, entonces, en reconocer la escasez del presupuesto como un 'indicio de inviabilidad' de los proyectos que las autoridades deberían desvirtuar si pretenden otorgar el consentimiento, por ejemplo, estableciendo condiciones que impliquen una mitigación efectiva de emisiones y/o justificando sólidamente la necesidad de desarrollar ese nuevo proyecto en particular. Aunque Preston no lo exprese de esta manera en el caso, tal proposición no se aleja demasiado de su razonamiento. La mejor ciencia

132 Sobre la consideración de los hechos en el Derecho administrativo, véase David Blanquer, Hechos, Ficciones, Pruebas y Presunciones en el Derecho Administrativo "Taking Facts Seriously", Tirant Lo Blanch, Valencia, 2006. 
disponible ${ }^{133}$ en conjunto con el reconocimiento gubernamental del estado de emergencia climática pueden justificar la racionalidad de este criterio.

Debe notarse que este enfoque debería lidiar con cuestiones de equidad nada simples ni despreciables ${ }^{134}$. Por ello, la aplicación del indicio sería fuertemente dependiente del caso, no solo con relación a las características del proyecto mismo, sino al contexto regional y nacional en el que se propone. Mientras que en países desarrollados la vara debería ser especialmente alta, en países en desarrollo podría existir una mayor flexibilidad. Aún así, se debería explicar cómo es que el proyecto impulsa el desarrollo, considerando todos los impactos negativos y los aspectos distributivos intra e intergeneracionales ${ }^{135}$. Con respecto a este último punto, la evaluación de los aspectos de equidad sobre la distribución de los beneficios y cargas del proyecto realizado por el juez Preston en su sentencia resulta relevante ${ }^{136}$.

Una segunda opción para la discusión sería entender que el enfoque exige contrastar el proyecto con los compromisos climáticos asumidos por cada estado (NDC y legislación doméstica), a los fines de asegurar coherencia entre los

133 "...[unprecedented,] rapid and far-reaching transitions in energy... systems" son necesarios para garantizar la permanencia dentro de un Sistema Tierra seguro. IPCC, "2018: Summary for Policymakers", en Valerie Masson-Delmonte et al. (eds.), Global Warming of $1,5^{\circ} \mathrm{C} \ldots$, cit. p. 17, <https://www.ipcc.ch/site/assets/uploads/sites/2/2019/05/SR15_SPM_version_report_LR.pdf> [útlima consulta, 18 de febrero de 2020]; Rockström, "Planetary Boundaries...", cit.

${ }^{134}$ Kartha, Lazarus y Tempest, "Fossil Fuel Production...", cit.; Henry Shue, Climate Justice: Vulnerability and Protection, Oxford University Press, 2014.

$135 \mathrm{El}$ anclaje jurídico del principio de equidad intergeneracional puede variar según el ordenamiento jurídico de actuación. En el caso analizado, como se mencionó, surge de la aplicación de los llamados 'principles of ecologically sustainable development', legislativamente consagrados. En otros litigios climáticos, los tribunales también se han expedido al respecto. Por ejemplo, en Colombia, la Corte Suprema recordó el carácter intergeneracional de la tutela constitucional en el caso 'Futuras Generaciones'; véase Corte Suprema de Justicia de Colombia (Sala de Casación Civil), Futuras Generaciones..., cit.; y en Sudáfrica, en el caso 'Earthlife Africa Johannesburg' el tribunal manifestó: "Sustainable development is at the same time integrally linked with the principle of intergenerational justice requiring the state to take reasonable measures protect the environment "for the benefit of present and future generations" and hence adequate consideration of climate change.", véase High Court of South Africa, Gauteng Division, Pretoria, Earthlife Africa Johannesburg..., cit., párr. 82. En ciertos ordenamientos, el principio cuenta con reconocimiento constitucional y/o legal expreso como en el caso de Argentina; véase Constitución de la República Argentina, artículo 41, y Ley General del Ambiente № 25.675, Argentina, Boletín Oficial de la República Argentina, artículo 4. Mientras que, en otros, se ha buscado su anclaje en la interpretación del más extendido principio de desarrollo sostenible o en la consagración del principio por el Derecho internacional; véase Claire Molinari, "Principle 3: From a Right to Development to Intergenenerational Equity", en Jorge Viñuales (ed.), The Rio Declaration on Environment and Development: A Commentary, Oxford University Press, 2015. ${ }^{136}$ New South Wales Land and Environmental Court, Gloucester Resources..., cit., párr. 398 y ss y 699 . 
diversos niveles de gobernanza ${ }^{137}$. Esta opción equivaldría a la utilización de presupuestos de carbono locales o nacionales, estén o no explícitos en el cuadro regulatorio. Debe advertirse que en este caso no se coloca al proyecto en perspectiva global sino en perspectiva nacional o local y, de este modo, se evita la espinosa cuestión de la equidad. La aplicación del enfoque implicaría que la autoridad explique detalladamente cómo el proyecto encaja en la planificación nacional, considerando otros proyectos en ejecución, aquellos aprobados en fase de construcción, e incluso los cierres previstos. Es evidente que esta tarea será más o menos simple dependiendo de la existencia de planes o programas que coordinen a nivel superior la dinámica entre el sector energético y los compromisos climáticos.

Este enfoque ayudaría a disminuir la mencionada brecha existente entre los proyectos de producción planificados y la reducción de emisiones prometidas en las NDC ${ }^{138}$. Sin embargo, dos cuestiones deben tenerse en cuenta ante esta propuesta. Por un lado, mientras que tal análisis sería útil para proyectos de producción destinada al consumo local, para proyectos fines de exportación difícilmente pueda ser utilizado debido a que, como se mencionó, las NDC y los planes nacionales en buena medida solo consideran emisiones territoriales. Dicho esto, nada obsta a que las NDC u otras medidas regulatorias incluyan metas de emisiones contabilizadas por el lugar de extracción ${ }^{139}$, lo que podría permitir este contraste. Por otro lado, debe notarse que los compromisos nacionales bajo el Acuerdo de París son, de momento, ampliamente insuficientes como marca el informe del Emissions Gap 2019140. Por ello, a los fines de dar cumplimiento a las metas fijadas en el régimen internacional y respetar el presupuesto de carbono, esta propuesta puede ser necesaria, pero no suficiente.

\section{CONCLUSIONES}

137 En High Court of South Africa, Gauteng Division, Pretoria, Earthlife Africa Johannesburg..., cit., párr. 90 el tribunal manifiesta: " $A$ climate change impact assessment is necessary and relevant to ensuring that the proposed coal-fired power station fits South Africa's peak, plateau and decline trajectory as outlined in the NDC and its commitment to build cleaner and more efficient than existing power stations".

${ }^{138}$ Stockholm Environment Institute et al., "The Production Gap...", cit., p. 20.

139 Ídem, p. 50.

140 United Nations Environment Programme, "Emission Gap...", cit. 
Alcanzar siquiera la meta más modesta del Acuerdo de París es, al menos, improbable si los estados no afrontan y se disponen a cerrar la brecha de producción de combustibles fósiles de la que son responsables. Como se ha advertido, con cada decisión en el sentido contrario los gobiernos se sumergen más profundamente en un carbon entanglementy aseguran (lock-in) trayectorias de emisiones más altas que las que el propio bienestar de su población justificaría. La ciencia ha indicado de diversas maneras, con la mayor certeza posible, las fronteras que no deben ser excedidas si se quiere continuar habitando un espacio planetario seguro. Todos estos límites se han revelado incómodos frente a la falsa ilusión del crecimiento ilimitado. El presupuesto de carbono representa uno más de estos límites incómodos.

En el caso analizado, tal concepto se inserta en el entramado jurídico-político que hace a la toma de decisiones de planeamiento como un parámetro, científicamente sólido, para la consideración de los impactos acumulativos de los proyectos de producción fósil en el sistema climático. Esta inserción se da, en el caso, con entidad suficiente para afectar los resultados sobre la viabilidad de proyectos en aparente contraposición con su integridad. No existen razones, a priori, para entender que tal inserción no podría darse en otras jurisdicciones en las que la evaluación de impactos ambientales sea una práctica consolidada y se hayan ratificado las metas del Acuerdo de París.

El análisis del caso y de sus repercusiones permiten extraer una serie de consideraciones de interés que a continuación se resumen. Primero, el enfoque adoptado por el juez puede ser utilizado para condicionar o denegar válidamente el consentimiento a nuevos proyectos debido, al menos en parte, a sus impactos climáticos. Segundo, tal situación posiblemente generará reacciones en determinados sectores interesados en mantener el statu quo, incluyendo a gobiernos fuertemente dependientes del sector fósil. Tercero, de ello se infiere que, en determinados contextos políticos, las posibilidades de aplicar el enfoque aquí acogido dependerán, en buena manera, de la existencia de órganos que detenten cierta independencia funcional, como en el caso lo son el tribunal y la IPC. Cuarto, esto no obsta, sin embargo, que autoridades competentes puedan adoptarlo como buenas prácticas, lo que sería esperable en algunos estados que han asumido el liderazgo y reconocido el estado de emergencia climática. 
Quinto, del estado de la jurisprudencia local, surge que - de momento- el enfoque del presupuesto de carbono debe ser considerado, no como un requisito de obligada aplicación, sino como una buena práctica con validez legal. Sexto, más allá de esto, puede pensarse que uno de los posibles pasos próximos de la jurisprudencia climática transnacional podría girar en torno al requerimiento legal de la utilización de parámetros para la adecuada valoración de los impactos acumulativos de proyectos sobre el sistema climático y, entre ellos, el del presupuesto de carbono. En este sentido, el caso aquí comentado tiene la potencialidad, dada su autoridad argumentativa, para inspirar la tarea de otros tribunales, sobre todo considerando la retroalimentación judicial existente en el ámbito de la litigación climática. Finalmente, la forma de aplicación del enfoque, de cara a la toma futura de decisiones, no está del todo clara. Por ello, se realizan dos propuestas: (i) la aplicación del enfoque como un 'indicio de inviabilidad' a ser desvirtuado para la aprobación de los proyectos y (ii) su aplicación en la forma de una evaluación más rigurosa de la coherencia entre el proyecto y la planificación nacional.

\section{BIBLIOGRAFÍA}

350.org, <350.org > [última consulta, 25 de mayo de 2020]

Bell-James, Justine y Collins, Brianna, "If We Don't Mine Coal, Someone Else Will": Debunking the "Market Substitution Assumption" in Queensland Climate Change Litigation", en Environmental and Planning Law Journal, Vol. 37, 2020.

Bell-James, Justine y Ryan, Sean, "Climate Change Litigation in Queensland: A Case Study of Incrementalism", en Environment and Planning Law Journal, Vol. 33, 2016.

Bernasconi, Amelia, "United Wambo open cut coal 'super pit' approved for NSW Hunter Valley with export conditions", $A B C, 30$ de agosto de 2019, $<$ https://www.abc.net.au/news/2019-08-29/united-wambo-approved-with-parisclimate-agreement-conditions/11460970> [última consulta, 7 de octubre de 2019]

Blanquer, David, Hechos, Ficciones, Pruebas y Presunciones en el Derecho Administrativo "Taking Facts Seriously", Tirant Lo Blanch, Valencia, 2006.

Burger, Michael y Wentz, Jessica, "Evaluating the Effects of Fossil Fuel Supply Projects on Greenhouse Gas Emissions and Climate Change Under NEPA", en William \& Mary Environmental Law and Policy Review, Vol. 44, 2020, p. 423-529. 
Cardesa-Salzmann, Antonio y Cocciolo, Endrius, "Global Governance, Sustainability and the Earth System: Critical Reflections on the Role of Global Law", en Transnational Environmental Law, Vol. 8, núm. 3, 2019, p. 437-461.

Commissioner for Productivity, "Terms of Reference, Review of Independent Planning Commission", <http://productivity.nsw.gov.au/sites/default/files/201910/IPC\%20Review\%20Terms\%20of\%20Reference.pdf> [última consulta, 25 de noviembre de 2019]

Consejo de Ministros, Referencia 21 de enero de 2020, Acuerdo por el que se aprueba la declaración del Gobierno ante la emergencia climática $y$ ambiental, <https://www.lamoncloa.gob.es/consejodeministros/referencias/documents/202 0/refc20200121.pdf> [última consulta, 25 de mayo de 2020]

Cox, Lisa "Massive Bylong valley coalmine in NSW blocked on environmental grounds", The Guardian, 18 de septiembre de 2019, $<$ https://www.theguardian.com/australia-news/2019/sep/18/massive-bylongcoalmine-in-nsw-blocked-on-environmental-grounds?CMP=share_btn_link> [última consulta, 2 de diciembre de 2019]

Cox, Lisa, "NSW considers laws to stop courts and planners blocking coalmines on climate grounds", The Guardian, 1 de octubre de 2019, $<$ https://www.theguardian.com/environment/2019/oct/02/nsw-considers-laws-tostop-courts-and-planners-blocking-coalmines-on-climate-grounds> [última consulta, 7 de octubre de 2019]

Cox, Lisa, "NSW moves to stop mine projects being blocked because of their overseas emissions", The Guardian, 22 de octubre de 2019, $<$ https://www.theguardian.com/environment/2019/oct/22/nsw-to-try-to-stopmine-projects-being-blocked-because-of-their-overseas-emissions?CMP=twt_aenvironment_b-gdneco> [última consulta, 22 de octubre de 2019]

Cox, Roger, "The Liability of European States for Climate Change", Utrecht Journal of International and European Law, Vol. 125, núm. 30, 2014.

Doraisamy, Jerome, "No appeal filed against 'groundbreaking' climate change judgment", LawyersWeekly, 10 de mayo de 2019, <https://www.lawyersweekly.com.au/wig-chamber/25613-no-appeal-filedagainst-groundbreaking-climate-change-judgment> [última consulta, 7 de octubre de 2019]

Duro, Juan Antonio, Giménez-Gómez, José-Manuel y Vilella, Cori, "The Allocation of $\mathrm{CO} 2$ emissions as a claims problem", en Energy Economics, Vol. 86, 2020.

Enríquez de Salamanca Sánchez-Cámara, Álvaro, Consideración del cambio climático en la evaluación de impacto ambiental de infraestructuras lineales de transporte, Tesis, Universidad Nacional de Educación a Distancia (España), 2017.

Friedman, Lisa, "Trump Rule Would Exclude Climate Change in Infrastructure Planning", The New York Times, 3 de enero de 2020 < 
https://www.nytimes.com/2020/01/03/climate/trump-nepa-climate-change.html> [última consulta, 8 de abril de 2020]

Gerrard, Michael, "Council on Environmental Quality Declares that Climate Change Is Already Covered in Environmental Impact Review, and No New Regulation Is Needed", Climate Law Blog, 13 de agosto de 2014, $<$ http://blogs.law.columbia.edu/climatechange/2014/08/13/council-onenvironmental-quality-declares-that-climate-change-is-already-covered-inenvironmental-impact-review-and-no-new-regulations-needed/> consulta, 25 de mayo de 2020]

[última

Green, Fergus, "Anti Fossil-fuel Norms", en Climatic Change, Vol. 150, 2018

Gurría, Ángel, "The climate challenge: Achieving zero emissions", OECD, 9 de octubre de $2013<$ <ttp://www.oecd.org/about/secretary-general/the-climatechallenge-achieving-zero-emissions.htm > [última consulta, 20 de abril de 2020]

Hilson, Chris, "Climate Change Litigation in the UK: An Explanatory Approach (or Bringing Grievance Back In)", en Fracchia, Fabrizio y Occhiena, Massimo (eds.), Climate Change: La Risposta del Diritto, Editoriale Scientifica, Nápoles, 2010, p. 421-436.

Hilson, Chris, "Framing Time in Climate Change Litigation", en Oñati Socio-legal Series, Vol. 9, núm. 3, 2019, p. 361-379.

Hughes, Lesley, "The Rocky Hill Decision: A Watershed for climate change action?", en Journal of Energy \& Natural Resources Law, Vol. 37, núm. 3, 2019.

Independent Planning Commission, "About us", $<$ https://www.ipcn.nsw.gov.au/about-us> [última consulta, 7 de octubre de 2019].

IPCC, "2018: Summary for Policymakers", en Masson-Delmonte, Valerie et al., (eds.), Global Warming of 1,5ㄷ. An IPCC Special Report on the impacts of global warming of $1.5^{\circ} \mathrm{C}$ above pre-industrial levels and related global greenhouse gas emission pathways, in the context of strengthening the global response to the threat of climate change, sustainable development, and efforts to eradicate poverty, 2018, <https://www.ipcc.ch/site/assets/uploads/sites/2/2019/05/SR15_SPM_version_r eport_LR.pdf> [útlima consulta, 18 de febrero de 2020].

Jaria i Manzano, Jordi, "La litigació climática a Espanya: una prospectiva", en Revista Catalana de Dret Ambiental, Vol. 9, núm. 2, 2018.

Kartha, Sivan, Lazarus, Michael y Tempest, Kevin, "Fossil Fuel Production in a $2^{\circ} \mathrm{C}$ World: The Equity Implications of a Diminishing Carbon Budget", en Stockholm Environment Institute: Discussion Brief, 2016, <https://mediamanager.sei.org/documents/Publications/Climate/SEI-DB-2016Equity-fossil-fuel-production-rents-LR.pdf> [última consulta, 11 de febrero de 2020].

Keep It in the Ground, <http://keepitintheground.org/> [última consulta, 25 de mayo de 2020].

Knaus, Christopher, "NSW Minerals Council pressured 'publicly and privately' for review of planning body", The Guardian, 21 de octubre de 2019, 
$<$ https://www.theguardian.com/australia-news/2019/oct/21/nsw-mineralscouncil-pressured-publicly-and-privately-for-review-of-planning-body> [última consulta, 25 de noviembre de 2019].

Lahn, Bård, "A History of the Global Carbon Budget”, en WIREs Climate Change, núm. e636, 2020.

Lazarus, Michael y van Asselt, Harro, "Fossil Fuel Supply and Climate Policy: Exploring the Road Less Taken", en Climatic Change, Vol. 150, 2018.

McCarthy, Joanne, "Korean Government-backed KEPCO is taking the only appeal path available to recover $\$ 750 \mathrm{~m}$ Bylong mine investment", Newcastle Herald, 18 de diciembre de 2019, $<$ https://www.newcastleherald.com.au/story/6547840/korean-energy-companykepco-seeks-judicial-review-of-landmark-bylong-coal-mine-refusal/> [última consulta, 26 de mayo de 2020]

Meinshausen, Malte et al., "Greenhouse-gas emission targets for limiting global warming to $2^{\circ} \mathrm{C}$ ", en Nature, Vol. 458, núm. 7242, 2009.

Molinari, Claire, "Principle 3: From a Right to Development to Intergenenerational Equity", en Viñuales, Jorge (ed.), The Rio Declaration on Environment and Development: A Commentary, Oxford University Press, 2015.

Muttit, Greg, "The Sky's Limit: Why the Paris Climate Goals Require a Managed Decline of Fossil Fuel Production", Oil Change International, 2016.

New South Wales, "Environmental Planning and Assessment Amendment (Territorial Limits) Bill 2019", <https://www.parliament.nsw.gov.au/bill/files/3717/First\%20Print.pdf> [última consulta, 11 de febrero de 2020].

New South Wales Government, Independent Planing Commission, "Review of Independent Planning Commission", <https://www.ipcn.nsw.gov.au/review-ofcommission> [última consulta, 25 de mayo de 2020].

New South Wales Government, Independent Planning Commission, "Statement of reasons for decision", 9 de agosto de 2019, $<$ https://www.ipcn.nsw.gov.au/resources/pac/media/files/pac/projects/2019/02/d artbrook-coal-mine-modification-7/determination/dartbrook-coal-mine-mod-7-statement-of-reasons-for-decision.pdf> [última consulta, 11 de febrero de 2020]

New South Wales Government, Independent Planning Commission, "Statement of reasons for decision", 29 de agosto de 2019, <https://www.ipcn.nsw.gov.au/resources/pac/media/files/pac/projects/2018/11/u nited-wambo-open-cut-coal-mine-project-ssd-7142/determination/uwjv--sor-final.pdf> [última consulta, 7 de octubre de 2019]

New South Wales Government, Independent Planning Commission, "Statement of reasons for decision", 18 de septiembre de 2019, <https://www.ipcn.nsw.gov.au/resources/pac/media/files/pac/projects/2018/10/b ylong-coal-project/determination/bylong-coal-project-ssd-6367--statement-ofreasons-for-decision.pdf> [última consulta, 2 de diciembre de 2019]. 
New South Wales Land and Environmental Court, "About us" <http://www.lec.justice.nsw.gov.au/Pages/about/about.aspx> [última consulta, 1 de abril de 2020]

New South Wales Land and Environmental Court, "Class 1: environmental planning and protection appeals" <http://www.lec.justice.nsw.gov.au/Pages/types_of_disputes/class_1/class_1.as px> [última consulta, 8 de octubre de 2019]

Nichols, Louise "Friends of the Upper Hunter want Dartbrook project evaluated in light of Rocky Hill ruling", The Singleton Argus, 9 de mayo de 2019, $<$ https://www.singletonargus.com.au/story/6114584/no-appeal-on-rocky-hilldecision/> [última consulta, 7 de octubre de 2019]

Pachauri, Rajendra Kumar et al., 2014: Cambio climático 2014: Informe de síntesis. Contribución de los Grupos de trabajo I, II y III al Quinto Informe de Evaluación del Grupo Intergubernamental de Expertos sobre el Cambio Climático, 2014 , $<$ https://www.ipcc.ch/site/assets/uploads/2018/02/SYR_AR5_FINAL_full_es.pdf $>$ [última consulta, 11 de febrero de 2020]

Parlamento Europeo, "European Parliament resolution of 28 November 2019 on the climate and environment emergency (2019/2930(RSP)", <http://www.europarl.europa.eu/doceo/document/TA-9-2019-0078_EN.html> [última consulta, 1 de diciembre de 2019]

Parliament of New South Wales, Environmntal Planning and Assessment Amendment (Territorial Limits) Bill 2019, <https://www.parliament.nsw.gov.au/bills/Pages/bill-details.aspx?pk=3717> [última consulta, 26 d mayo de 2020]

Peel, Jaqueline, Osofsky, Hari y Foerster, Anita, “A ‘Next Generation’ of Climate Change Litigation?: an Australian Perspective", en Oñati Socio-Legal Series, Vol. 9, núm. 3, 2019.

Peel Jaqueline y Lin, Jolene, "Transnational Climate Litigation: The Contribution of the Global South", en American Journal of International Law, Vol. 113, núm. 4, 2019.

Peel, Jaqueline y Osofsky, Hari, Climate Change Litigation: Regulatory Pathways to Cleaner Energy, Cambridge University Press, 2015.

Penelli, Sebastián, "Regresa el barril "criollo" de petróleo a u\$s45 con fuerte respaldo de YPF, provincias y sindicatos", ámbito.com, 7 de mayo de 2020, $<$ https://www.ambito.com/barril-criollo/regresa-el-petroleo-us45-fuerte-respaldoypf-provincias-y-sindicatos-n5100804> [última consulta, 14 de mayo de 2020]

Power, Julie "Independent Planning Commission to be final arbiter only on state's most contentious projects", The Sydney Morning Herald, 1 de febrero de 2020, $<$ https://www.smh.com.au/politics/nsw/independent-planning-commission-to-befinal-arbiter-on-only-state-s-most-contentious-projects-20200201-p53wsx.html> [última consulta, 11 de febrero de 2020]

Preston, Brian, "Mapping Climate Change Litigation”, en Australian Law Journal, Vol. 92, 2018. 
Rafaty, Ryan, Srivastav, Sugandha y Hoops, Björn, "Revoking Coal Mining Permits: An Economic and Legal Analysis", en Climate Policy, 2020 (próximo).

Rockström, Johan, et al., "Planetary Boundaries: Exploring the Safe Operating Space for Humanity", en Ecology and Society, Vol. 14, núm. 2, 2009.

Rocky Hill Coal Project, "Location", <https://www.rockyhillproject.com.au/projectoverview/location/> [última consulta, 7 de octubre de 2019]

Rocky Hill Coal Project, "Rocky Hill Coal Project will not proceed", 8 de mayo de 2019, <https://www.rockyhillproject.com.au/2019/05/rocky-hill-coal-project-willnot-proceed/> [última consulta, 7 de octubre de 2019]

Rogelj, Joeri et al., "2018: Mitigation Pathway Compatible with $1.5^{\circ} \mathrm{C}$ in the Context of Sustainable Development" en Masson-Delmonte, Valerie et al., (eds.), Global Warming of $1,5^{\circ} \mathrm{C}$. An IPCC Special Report on the impacts of global warming of $1.5^{\circ} \mathrm{C}$ above pre-industrial levels and related global greenhouse gas emission pathways, in the context of strengthening the global response to the threat of climate change, sustainable development, and efforts to eradicate poverty,

2018, <https://www.ipcc.ch/site/assets/uploads/sites/2/2019/05/SR15_Chapter2_Low_ Res.pdf> [última consulta, 11 de febrero de 2020]

Rogelj, Joeri et al., "Estimating and tracking the remaining carbon budget for stringent climate targets", en Nature, Vol. 571, núm. 7765, 2019.

Ruda-Gonzalez, Albert, "Perspectives de la litigació pel canvi climàtic arran del cas Urgenda", en Revista Catalana de Dret Ambiental, Vol. 9, núm. 2, 2018.

Russell, Stephen, "A Recommended Methodology for Estimating and Reporting the Potential Greenhouse Gas Emissions from Fossil Fuel Reserves", World Resources Institute, Working Paper, 2016, $<$ https://wriorg.s3.amazonaws.com/s3fs-

public/A_Recommended_Methodology_for_Estimating_and_Reporting_the_Pot ential_Greenhouse_Gas_Emissions_from_Fossil_Fuel_Reserves.pdf> [última consulta, 11 de febrero de 2020]

Setzer, Joana y Byrnes, Rebecca, "Global trends in climate change litigation: 2019 snapshot", Grantham Research Institute on Climate Change and the Environment, Centre for Climate Change Economics and Policy, London School of Economics and Political Science, Policy Report, 2019.

Shue, Henry, Climate Justice: Vulnerability and Protection, Oxford University Press, 2014.

Steffen, Will et al., "Trajectories of the Earth System in the Anthropocene", en Proceedings of the National Academy of Sciences, Vol. 113, núm. 33, 2018.

Stockholm Environment Institute et al., "The Production Gap: The discrepancy between countries' planned fossil fuel production and global production levels consistent with limiting warming to $1.5^{\circ} \mathrm{C}$ or $2^{\circ} \mathrm{C}$, 2019 , $<$ http://productiongap.org/wp-content/uploads/2019/11/Production-Gap-Report2019.pdf> [última consulta, 11 de febrero de 2020] 
Thunberg, Greta, No One Is Too Small to Make a Difference, Penguin Books, Reino Unido, 2019.

United Nations Environment Programme, "Emissions Gap Report 2019", $<$ https://wedocs.unep.org/bitstream/handle/20.500.11822/30797/EGR2019.pdf? sequence $=1$ \&isAllowed $=\mathrm{y}>$ [última consulta, 11 de febrero de 2020]

United Nations Environment Programme, "Environmental Rule of Law: First Global Report", 2019, $<$ https://wedocs.unep.org/bitstream/handle/20.500.11822/27279/Environmental rule_of_law.pdf?sequence=1\&isAllowed=y> [última consulta, 14 de enero de 2020]

White, Robert, Hallinan, Jemilah y Rayment, Belinda, "Climate Change Takes Centre Stage in Land and Environment Court", Law Society of NSW Journal, núm. 54, 2019.

World Resources Institute y World Business Council for Sustainable Development, "The Greenhouse Gas Protocol: A Corporate Accounting and Reporting Standard", 2004 , <https://ghgprotocol.org/sites/default/files/standards/ghg-protocol-revised.pdf> [última consulta, 11 de febrero 2020]

\section{NORMATIVA}

Acuerdo de París, París, 12 de diciembre de 2015, United Nations Treaty Collection, artículo

2, $<$ https://treaties.un.org/doc/Treaties/2016/02/20160215\%2006-

03\%20PM/Ch_XXVII-7-d.pdf> [última consulta, 13 de febrero de 2020]

Constitución de la República Argentina, artículo 41.

Directiva 2014/52/UE del Parlamento Europeo y del Consejo, de 16 de abril de 2014, por la que se modifica la Directiva 2011/92/UE, relativa a la evaluación de las repercusiones de determinados proyectos públicos y privados sobre el medio ambiente, Unión Europea, 25 de abril de 2015, Diario Oficial de la Unión Europea.

Ley 21/2013, de 9 de diciembre, de evaluación ambiental, España, 11 de diciembre de 2013, Boletín Oficial del Estado.

Ley 25.675, Ley General del Ambiente, Boletín Oficial de la República Argentina, 28 de noviembre del 2002, artículo 4.

New South Wales Environmental Planning and Assessment Act 1979 No. 203, Division $8 . \quad$ Appeals-development consents, <https://www.legislation.nsw.gov.au/\#/view/act/1979/203/part8/div8.3> [última consulta 25 de mayo de 2020]

New South Wales Land and Environment Court Act 1979 No. 204, Section 57, <https://www.legislation.nsw.gov.au/\#/view/act/1979/204/part5/div2/sec57> [Última consulta, 27 de mayo de 2020] 
New South Wales Protection of the Environment Administration Act 1991 No. 60. Part 3.6(2), < https://www.legislation.nsw.gov.au/ /pdf/view/act/1991/60/whole> [última consulta, 4 de junio de 2020]

\section{JURISPRUDENCIA}

Corte Suprema de Justicia de Colombia (Sala de Casación Civil), Futuras Generaciones v. Presidencia de la República de Colombia, STC4360-2018, sentencia del 5 de abril de 2018.

England and Wales High Court (Administrative Court), H J Banks \& Company Ltd. v. Secretary of State for Housing Communities and Local Government, et al., [2018] EWHC 3141 (Admin), sentencia del 23 de noviembre de 2018.

High Court of Ireland, Friend of the Irish Environment v. Fingal County Council, Case 2017 No. 201 JR, sentencia del 21 de noviembre de 2017.

High Court of South Africa, Gauteng Division, Pretoria, Earthlife Africa Johannesburg $v$. The Minister of Environmental Affairs et. al.,Case No.: 65662/16, sentencia del 8 de marzo de 2017.

New South Wales Land and Environmental Court, Australian Coal Alliance Incorporated v Wyong Coal Pty Ltd [2019] NSWLEC 31, sentencia del 22 de marzo de 2019.

New South Wales Land and Environmental Court, Gloucester Resources Limited v Minister for Planning [2019] NSWLEC 7, sentencia del 8 de febrero de 2019.

New South West Land and Environment Court, Gray v. The Minister of Planning and Ors, Case No.: 40870/2006, sentencia del 27 de noviembre de 2006.

Tercer Tribunal Ambiental de Chile, Corporación Privada para el Desarrollo de Aysén y ots. v. Comité de Ministros, R 42-2016, sentencia del 4 de enero de 2018.

Tercer Tribunal Ambiental de Chile, Simonetti Grez, Gabriela y ots. v. Servicios de Evaluación Ambiental, R 77-2018, sentencia del 20 de agosto de 2019.

United States Court of Appeals, $9^{\text {th }}$ Circuit, Center for Biological Diversity $v$. National Highway Traffic Safety Administration, 508 F.3d 508, sentencia del 15 de noviembre de 2007.

United States Court of Appeals, $10^{\text {th }}$ Circuit, WildEarth Guardians et al. v. U.S. Bureau of Land Management et al., Case No. 15-8109, sentencia del 15 de septiembre de 2017.

United States District Court for the District of Alaska, Alaska Wilderness League, et al. v. Sally Jewell et al., Case No. 1:08-cv-00004-RRB, memoria inicial de los demandantes del 28 de agosto de 2015.

United States District Court fo the District of Colorado, Wilderness Workshop, et al. v. U.S. Bureau of Land Management, et al., Case No. 1:18-cv-00987, demanda, 26 de abril de 2018. 
United States District Court for the District of Columbia, WildEarth Guardians, et al. v. Zinke, et al., 16-1724(RC), sentencia del 19 de marzo de 2019.

United States District Court for the District of Columbia, WildEarth Guardians, et al. v. Zinke, et al., 16-1724(RC), moción para sentencia sumaria del 6 de enero de 2020.

United States District Court for the District of Montana Great Falls Division, Western Organization of Resource Councils, et al. v. U.S. Bureau of Land Management, et al., CV 16-21-GF-BMM, sentencia del 26 de marzo de 2018.

United States District Court for the District of Oregon Eugene Division, Kelsey Cascadia Rose Juliana, et. al. v. United States of America, et. al., Case No. 6:15cv-01517-TC, sentencia del 10 de noviembre de 2016. 